\title{
Estudios funcionales de artefactos líticos de Cueva de las Manos, Río Pinturas, Santa Cruz, Argentina
}

RMA

Arqueología
G. Roxana Cattáneo'

Ana M. Aguerre 2

\begin{abstract}
${ }^{1}$ CONICET, Laboratorio de Análisis Macro y Microscópico de Materiales Líticos, Museo de Antropología, Facultad de Filosofía y Humanidades, Universidad Nacional de Córdoba. E-mail: roxanacattaneo@gmail.com

${ }^{2}$ CONICET, Instituto de Arqueología, Facultad de Filosofía y Letras-Universidad de Buenos Aires. E-mail: amaguerre@gmail.com
\end{abstract}

\begin{abstract}
Resumen
El presente trabajo tiene como objetivo presentar los resultados del estudio funcional o de microhuellas de una muestra de raspadores procedentes de la excavación del sitio Cueva de las Manos. Fueron seleccionados entre los provenientes de las capas 4C, 5 y 6, que cuentan con fechados radiocarbónicos entre 1610 años AP a 9300 años $A P$. Por un lado nos interesó poder profundizar sobre qué materia prima trabajaron estos raspadores, ya que nunca había podido ser analizado en estudios anteriores. Por otro lado nos interesa ampliar el estudio de la variabilidad morfológica en relación a la variabilidad funcional en los raspadores ya que en este sitio es notable la variedad de instrumentos clasificados como raspadores y cepillos (rabots). Estos nuevos resultados permitirán además profundizar la discusión presentada en trabajos anteriores donde se infirió una tendencia hacia una diferenciación entre ciertos subgrupos de instrumentos cuyos últimos usos conocidos fueron sobre un solo tipo de materia prima mientras que otros se asociaron con el trabajo de al menos dos tipos de materiales. Para este trabajo se utilizaron las observaciones realizadas con el Microscopio Láser Confocal de Barrido BioRad MRC600, luego analizadas a través de software de reconocimiento de imágenes "PHILOS".
\end{abstract}

Palabras clave: Cueva de las Manos, raspadores, análisis funcional, diseño.

Lithic artifacts functional studies from Cueva de las Manos, Río Pinturas, Santa Cruz, Argentina

\begin{abstract}
We present the results of microwear studies of a sample of scrapers, from the excavations at the site Cueva de las Manos-layers 4c, 5 and 6-, dated between 1610 bp to 9300 years bp. We are interested in defining on what type of raw material these scrapers worked, since this subject wasn't previously analyzed. On the other hand we are interested in extending the study of the morphologic variability of scrapers, in relation to their functional variability. Especially considering that this site presents a remarkable number of instruments classified as scrapers and rabots. These new results will allow going deeper in the discussion started by Cattaneo in previous works. A differentiation was established in them between certain subgroups of scrapers working only on one type of material and other groups which combined several types- at least two of them. Also, we reintroduce the observations made with the Laser Confocal Scanning Microscope BioRad MRC600, that were also analyzed with the "PHILOS" software for image recognition.
\end{abstract}

Keywords: Cueva de las Manos, scrapers, functional analysis, design.

El presente trabajo tiene dos objetivos: por un lado, presentar los avances en el estudio del diseño y la función de instrumentos líticos arqueológicos provenientes de las campañas de 1973, 1974 y 1977 realizadas por Gradin, Aschero y Aguerre de la excavación del sitio Cueva de las Manos, Alto Río Pinturas, (ARP1) noroeste de la provincia de Santa Cruz (Gradin et al. 1976 y Aguerre 1977) (Figura 1).

Por otro, presentar un caso de aplicación de una nueva metodología de análisis funcional de base microscópica que utiliza un microscopio de barrido láser confocal (MBLC) y un software de desarrollo propio (PHILOS) (Figura 2). Dicha metodología es el resultado de un programa de investigación iniciado en 2005 por una de nosotras (GRC) con un grupo de especialistas en física láser de la UNLP-CIC-CONICET ${ }^{1}$ y propone un análisis

1 Proyectos ANPYCT-FONCYT PICT 2004 n² 25347. “Diseño y función en el área arqueológica Río Pinturas (Santa Cruz, Argentina): el estudio 


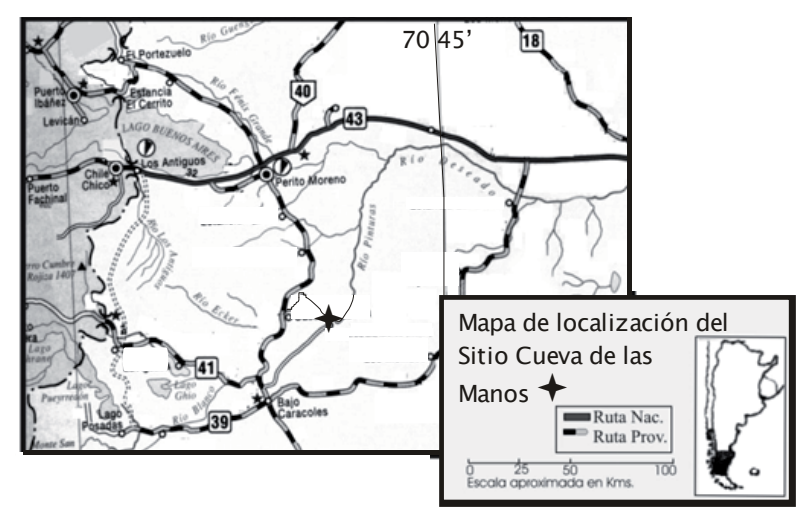

Figura 1. Localización de la Cueva de las Manos.

objetivo basado en comparaciones entre imágenes obtenidas de filos de instrumentos experimentales (Figura 3) y arqueológicos.

Para introducirnos en el problema haremos primero una breve descripción del caso que nos ocupa, de manera de entender la historia del problema y luego de la metodología utilizada en este trabajo, que si bien no es exhaustiva dado que ya ha sido publicada previamente (Cattáneo et al. 2007a, b, y c; Cattáneo 2007; Cattáneo y Aguerre 2008) permitirá entender la técnica utilizada para realizar nuestras interpretaciones.

Los materiales líticos provenientes de ARP 1 han permitido durante años profundizar discusiones sobre temas diversos referidos a la tecnología y tipología lítica de los grupos cazadores-recolectores que habitaron el área. Sobre la base de los primeros trabajos de excavación en ARP $1\left(31 \mathrm{~m}^{2}\right)$ Gradin et al. (1976) plantearon la existencia de seis unidades estratigráficas en Cueva de las Manos. Luego, esto se vería confirmado por excavaciones posteriores $\left(11 \mathrm{~m}^{2}\right.$ ) (Aguerre 1977; Gradin et al. 1979).

Los autores antes citados, desde los inicios del estudio del material lítico proveniente de este sitio, ya se plantearon ciertos interrogantes referidos a la vinculación entre los niveles culturales que definieron en estas capas en lo relativo al análisis tipológico. Una de dichas cuestiones se refería al orden dominante de los grupos tipológicos y analizaba en cada uno de ellos ciertos caracteres morfológico-funcionales predominantes considerando los filos complementarios, los rastros de utilización macroscópicos y los ángulos de biseles de las aristas activas (Gradin et al. 1976: 222).

Ellos proponían para cada una de estas capas la aparición de distintas recurrencias de subgrupos de raspadores: en las tres capas que consideraremos aquí se recuperaron en diferentes proporciones raspadores de filo frontal corto, frontales o angulares restringidos y fronto-laterales exten-

de los instrumentos líticos a través de técnicas cuantitativas" y FCNyMUNLP N462: "Tecnología lítica en grupos cazadores-recolectores prehistóricos de Argentina: perspectivas experimentales y arqueológicas", ambos dirigidos por R. Cattáneo.

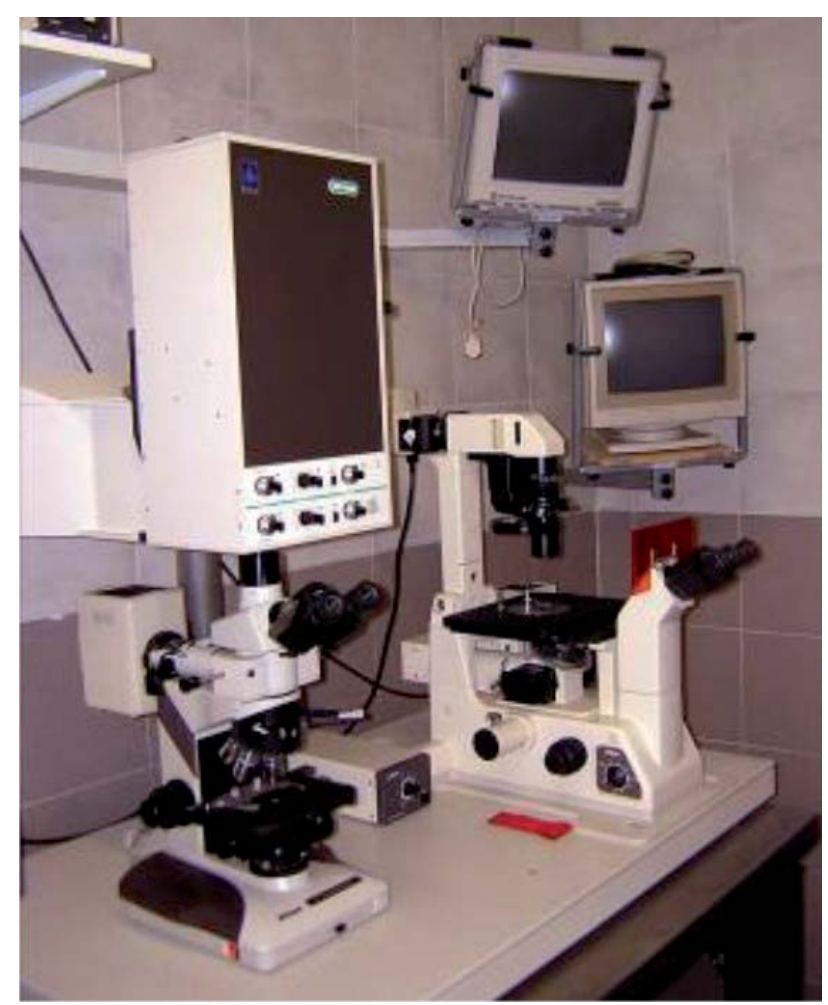

Figura 2. CLSM Biorad MRC 600 del Laboratorio de Procesamiento Láser dependiente del Centro de Investigaciones Ópticas (CIC/CONICET/UNLP) donde se realizaron los análisis.

didos, aún en la capa 4c la más potente ocupación de la cueva (para una descripción extensa de los materiales y las hipótesis ver Gradin et al. 1976:226, 231; 1979:208, 211 y 1987:121; Aguerre 1977:133 a 140, 1979: 39 y 40, y Aschero 1987: 21 y 22). En trabajos posteriores se postuló respecto de la caracterización del subgrupo de los raspadores frontales de filo corto la presencia de uno o dos filos complementarios como parte integrante de este subgrupo (Aguerre y Patiño 1991: 210 a 213 y 217).

El estudio de esas variaciones se hizo en el marco de análisis que profundizaban el estudio del modo en el que los instrumentos podían haber sido utilizados, o contexto de uso, y como esto se vinculó a la organización de la tecnología, es decir con todos los aspectos que involucraron la fabricación, uso, mantenimiento y/o reciclaje de los instrumentos durante su ciclo de vida, hasta que fueron descartados (Aschero 1987:18 y 19). Sin embargo, al no haberse realizado estudios de microscopía para realizar atribuciones funcionales, muchos de los interrogantes quedaron sin respuesta (Gradin et al. 1976,1979; Aguerre 1977).

En este trabajo, tomando en cuenta estos antecedentes se seleccionó una muestra de raspadores (sensu Aschero, 1975) provenientes de tres de esas unidades: la capa 4c (datada en $1610 \pm 60$ años ap), la capa 5 (fechada en 3380 \pm 80 años ap) y la capa 6 (con dos dataciones de 9320 \pm 90 años ap y 9300ะ90 años ap) (Gradin et al. 1976 y 1979; Aguerre 1977).

Es así como los objetivos particulares de nuestro trabajo se focalizaron en el análisis funcional de base microscópica 

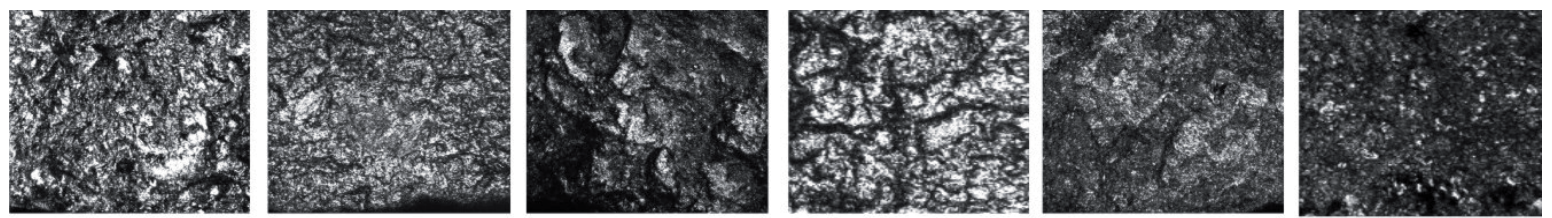

Figura 3. Ejemplos de imágenes obtenidas con el CLMS a 100X en filos experimentales de tobas vítreas silicificadas luego de 60 minutos de trabajo de raspado por acción transversal sobre (de izquierda a derecha): cuero fresco, cuero seco, hueso fresco, hueso seco, madera dura y madera blanda.

de los raspadores y/o cepillos (o rabots), para establecer qué tipo de relaciones existen entre las variaciones de diseño y funcionalidad dentro de estos subgrupos para los distintos momentos cronológicos. Es decir, el caso que presentaremos aquí permitirá ampliar el estudio de la variabilidad morfológica en relación a la variabilidad funcional, para discutir expectativas en cuanto al porqué de la permanencia de ciertas formas de diseño a través del tiempo. El paso que aquí presentamos no es más que el inicio en ese proceso de análisis, que ha buscado a través del estudio de los filos, desde una metodología objetiva, continuar resolviendo cuestiones tanto metodológicas como de interpretación del registro. Es así, como dentro de la complejidad de este universo de análisis, pretendemos dar una primera aproximación a lo que entendemos como una realidad compleja y diversa, que puede informarnos sobre los cambios y continuidades en los modos de producción y uso del recurso roca, vinculados a las ocupaciones estudiadas en ARP1.

El abordaje de este tema desde la perspectiva funcional no fue trabajado previamente en el área de investigaciones del río Pinturas, aunque sabemos que sí ha tenido un gran adelanto en otras áreas de pampa y patagonia argentina (i.e. Álvarez et al. 2000; Álvarez 2003, 2004; Cattáneo 2002; 2006; Cattáneo y Fernández 2005; Leipus 2001, 2004; Leipus y Mansur 2007; Mansur 1999; Mansur y Lasa 2004; Paunero y Castro 1997, 2001; Yacobaccio 1988) así como en el resto del mundo donde este tipo de trabajo ha sido desarrollado desde múltiples perspectivas con interesantes resultados (e.g. Anderson et al. 2004; Close 2002; Collin y Jardón-Giner 1993; Hayden 1986; Jardón-Giner y Sacchi 1994; Phillibert 1994; Winiarska-Kabaonska 1988). No deseamos sin embargo extendernos aquí sobre este tema que ha sido objeto de presentaciones anteriores (Cattáneo et al. 2007 a, b, y c; Cattáneo 2007 y Cattáneo y Aguerre 2008), sino más bien hacer hincapié en las diferencias básicas entre los estudios tradicionales de base microscópica (Bamforth 1988; Bamforth et al. 1990; Gendel y Pirnay 1982; Grace 1990, 1996; Holley y Del Bene 1981; Hurcombe 1988; Keeley 1974, 1976, 1978, 1980; Keeley y Newcomer 1977; Mansur 1999; Moss 1987; Newcomer et al. 1986, 1987, 1988; Newcomer y Keeley 1979; Rees et al. 1991; Semenov 1964; Vaughan 1981, 1985; ) y aquellos trabajos donde se ha intentando plantear análisis de base objetiva similares a los que aquí proponemos y venimos desarrollando (e.g. Grace et al. 1985, 1987; también ver Grace 1989, 1993, 1996 para "sistemas expertos", escaneos digitales y análisis de textura con histogramas (Knutsson et al. 1988; Mansur y Srehnisky 1996), interferometría (Dumont 1982), perfilometria (Akoshima 1981; Beyries et al.1988), microscopía de fuerza atómica (Kimball et al. 1995), y geometría fractal (Rees et al. 1991; Russ 1993, 1994; Stemp y Stemp 2001; 2003; e incluso recientemente una metodología similar con microscopía láser confocal (Evans y Donahue 2008).

Como puede observarse por los trabajos citados, hace ya más de veinte años que la comunidad arqueológica aboga por el desarrollo de nuevas líneas de investigación, incluso desde posturas muy críticas (e.g. Grace 1989). Siguiendo esta líneas tradicionales pero con los nuevos enfoques, una de nosotras (GRC) se ha especializado en el tema y en principio un aspecto metodológico importante que decidió incorporar es el uso del MBLC. Este microscopio, en nuestro caso marca BioRad MRC600, permite aplicar una técnica de observación no destructiva, ya que los artefactos líticos no requieren preparación previa, a excepción de la limpieza tradicional. Esta técnica de observación utiliza un microscopio Nikon invertido, lo que garantiza el espacio suficiente para la ubicación de muestras grandes (aproximadamente 15 x15 x $15 \mathrm{~cm}$ ). Las imágenes obtenidas a través de un barrido láser que demora segundos relevan la topografía de los filos en tres dimensiones con mayor resolución lateral $(x, y)$ que los microscopios convencionales (lo que implica la capacidad de resolver o identificar dos puntos próximos que en un microscopio de reflexión serian identificados como el mismo punto). Además, sólo forma imagen de la parte del espécimen que se encuentra en su plano focal por lo que los sucesivos planos paralelos relevados por barrido según el eje óptico (z) pueden espaciarse cada $250 \mathrm{~nm}$ (si la longitud de onda del láser utilizado es de 488nm), situación que puede interpretarse como una profundidad de campo infinita, generándose así una imagen completamente en foco (Figura 3). El barrido según (z) puede extenderse por $30 \mathrm{~mm}$, con lo que el procesamiento de la serie de imágenes digitales, que son en escala de grises, permite una reconstrucción espacial fidedigna de los filos o aristas activas de los instrumentos estudiados.

En cada una de las imágenes obtenidas de los filos arqueológicos, en la magnificación deseada (100X, 200X 400X, etc.), seleccionamos zonas de 150 por 150 píxeles, que constituyen el lote de imágenes a analizar. Luego, aplicamos el software de reconocimiento de filos (PHILOS) que compara las imágenes con una base de 600 imágenes experimentales obtenidas previamente por nosotros (Cattáneo et al. 2007b) (e.g. Figura 3). El mencionado programa basa su análisis en distintos descriptores de segundo orden obtenidos en base a las matrices de co-ocurrencia construidas sobre todo el rango dinámico de cada imagen, es decir los valores de grises de 0 a 255 (Lepistö et al. 2003; Partio et al. 2002; Walker et al. 1995). 
En nuestros trabajos hemos podido observar que el estado de conservación de los materiales arqueológicos de ARP 1 es excelente, superando los promedios habituales de piezas que pudieron ser estudiadas en otros contextos de Patagonia continental (Cattáneo 2002). Sin embargo, para aquellos casos donde las piezas se encuentran afectadas especialmente por pátinas, los estudios funcionales se ven notoriamente afectados por la desaparición y/o enmascaramiento de las microhuellas en los filos de los instrumentos (e.g. Mansur 1999), por lo que este aspecto también debe ser tenido en cuenta a la hora de estudiar los contextos. Aunque cuando fue excavado este sitio no se tomaban entonces detalles tan específicos (según AMA), es posible hoy recuperar esta información por la vía microscópica observando detalladamente como los distintos procesos físico-químicos han afectado la superficie de los instrumentos. Profundizar estos aspectos, obteniendo imágenes de bases de datos comparativas de procesos naturales, es un tema que está en nuestra agenda de trabajo futuro.

\section{En cuanto al análisis de las características macros- cópicas de diseño o CMD: análisis tipológico- mor- fológico.}

Una primera etapa fue continuar, por un lado, con el uso de la clasificación de Aschero (1975 y 1983) para la descripción morfológica y asignación a un grupo y subgrupo tipológico de los instrumentos, para entender la diversidad de diseños presentes. Deseamos aclarar que si bien los estudios tipológico-morfológicos ya se hicieron, incluiremos en nuestros análisis (siguiendo a Aschero 1975):

- la posición del filo (frontal, angular, lateral y frontolateral),

- la extensión del filo (en $\mathrm{mm}^{2}$ ),

- la forma primaria y secundaria del filo,

- el tipo de sostén para la cinemática o acción de uso: prensión digital, digito-palmar o con enmangue (sobre la base del análisis morfológico).

También consideraremos algunos criterios métricos que nos aportan a entender la relación entre la morfometría y el estudio funcional que queremos encarar. Así, se sumaron como relevantes en este trabajo el peso de la pieza (en g) y el volumen (largo por ancho por espesor, en $\mathrm{mm}^{3}$ ).

Aschero (1975:58) propone el grupo de los raspadores sobre la base de una función primaria basada en los caracteres macroscópicos, en relación a un modo de acción y movimiento. Reconoce un total de 8 subgrupos tipológicos y para su caracterización utiliza la articulación de caracteres morfológico-funcionales donde toma en cuenta:

- la forma primaria del filo,

- la forma del filo sobre el bisel,

- su espesor,

- la extensión relativa del filo sobre el borde de la pieza,
Posteriormente Aschero y Hocsman (2004:11) incluyen además:

- la posición relativa del filo o punta respecto al eje longitudinal de la pieza y

- la relación de convergencia entre filos consecutivos o aristas laterales de una punta destacada.

Nuestra propuesta es analizar la relación entre cada una de estas variables y la función asignada por los estudios microscópicos a cada pieza para tratar de entender las relaciones entre la morfometría y la función en los contextos con distintas cronologías, allí donde están representados los mismos subgrupos tipológicos.

\section{En cuanto al análisis funcional de base microscópica}

Ya nos hemos explayado anteriormente sobre la metodología que usamos, por lo que remitimos al lector a aquella bibliografía (Cattáneo et al. 2007a, b y c; Cattáneo 2007). En este caso, en primer lugar, se realizó una limpieza con agua jabonosa y acetona de cada pieza para estudiar las aristas activas de los instrumentos utilizando el Microscopio Láser Confocal de Barrido BioRad MRC600.

Posteriormente se analizaron las imágenes obtenidas de cada pieza con sus distintos filos, para la asignación de su probable funcionalidad, a través de software de reconocimiento de imágenes "PHILOS" (Gulich y Lofeudo 2005) siguiendo los criterios establecidos en Cattáneo et al. (2007b). El hecho de estudiar y relevar toda la superficie de los filos permite recuperar en distintos sectores del instrumento parte de la historia de uso de las piezas, por lo que en algunos casos se ha podido determinar más de un uso posible.

Finalmente se integró el análisis de cada pieza, macroscópico y microscópico, y se realizaron los análisis comparativos, por capa, para discutir algunas tendencias.

\section{La muestra estudiada}

Del total de los raspadores recuperados en la excavación se seleccionaron 50 piezas (ver Tabla 1), siguiendo ciertos criterios para la selección de la muestra a estudiar:

- que fueran piezas enteras, dado que el objetivo era comparar el diseño de cada instrumento y la/s función/ es desempeñadas.

- que tuvieran buen estado de conservación a ojo desnudo y lupa, dado que se llevaría a cabo el estudio microscópico de los bordes activos.

- que fueran de una materia prima determinada dado que la técnica microscópica de análisis funcional aquí empleada utiliza el método comparativo (con bases de datos de imágenes de filos activos de instrumentos de tobas vítreas silicificadas, jaspes y ópalo).

Dentro de la muestra se incluyó un conjunto de cinco instrumentos pertenecientes a capa 6 clasificados como 
raspadores "o rabots", que además presentaban sustancias adheridas en los filos activos. Dichos instrumentos fueron analizados mediante metodología funcional, pero previamente se hizo un estudio de espectrofotometría infrarroja (FTIR) para determinar qué tipos de residuos quedaron en los filos utilizados. Los resultados se encuentran presentados en otro trabajo. Sumariamente podemos decir que en todos los casos los residuos pertenecían a proteínas animales degradadas provenientes de cuero de Lama guanicoe (Cattáneo et al. 2007a).

Del total de la muestra seleccionada, luego de las primeras observaciones microscópicas, tuvieron que ser descartados nueve instrumentos debido a que algunas piezas no presentaron microrrastros de utilización por motivos diversos. Mayormente éstos fueron procesos post-depositacionales que alteraron la superficie eliminando la posibilidad de recuperar microhuellas de utilización; otros, presentaban pátinas por procesos naturales, o bien, en algunos casos la presencia de tinta china o barniz del rotulado no permitieron el análisis (i.e. capa 4c piezas h18, f3). También en un caso de capa 5 las variaciones de la materia prima (obsidiana) no permitieron su análisis comparativo con las bases de datos de imágenes con que se cuenta.

Con los instrumentos restantes se confeccionó una base de datos por capa (ver Tablas 2, 3 y 4). Allí puede observarse que sobre el total de 41 piezas, se estudiaron y describieron un total de 109 filos. En su mayoría, además de los filos descriptos como de raspador (52), se describieron en muchos casos (53) filos largos o complementarios (sensu Gradin et al. 1976: 236). Los cuatro casos restantes corresponden a 1 muesca y 3 raedera/cuchillo o dorso. En general, hay escasos instrumentos compuestos (3 casos) o dobles (4 casos).

Si bien en un primer momento al comenzar nuestros estudios sobre las colecciones de Cueva de las Manos realizamos un muestreo orientado hacia el estudio de cierto subgrupo de raspador -los raspadores frontales de filo corto- (Cattáneo 2007) al realizar un segundo muestreo para el trabajo que aquí presentamos, decidimos profundizar el estudio de la variabilidad morfológico-funcional, para lo cual se consideró mantener la representatividad de la variabilidad del conjunto total de acuerdo a los trabajos publicados (Aguerre 1977; Gradin et al. 1976; Gradin et al. 1979).

\section{Resultados}

En cuanto al análisis de las características macroscópicas de diseño o CMD.

\section{a) Variaciones de los subgrupos tipológicos}

Para la muestra analizada de los raspadores de capa 6 se describió la presencia de 9 variaciones de subgrupos tipológicos del grupo de los raspadores (a los que se suman otros que no entran dentro de la definición del subgrupo pero nos parece importante no dejar de mencionar: los filos largos, un caso de raedera/cuchillo/dorso y un caso de muesca). Encontramos por un lado los filos descriptos como de los distintos subgrupos de raspadores y también "filos largos", que en general son paralelos o inclinados, que presentan evidencias a nivel macro de rastros complementarios. Para las muestras de las otras dos capas la representatividad de los subgrupos de los raspadores es mucho menor observándose 3 subgrupos para capa 5, más los filos largos o complementarios, y 4 subgrupos tipológicos para capa $4 \mathrm{c}$ a los que se suman los filos largos (para un detalle de las cantidades atribuidas a cada capa ver Tabla 5).

De todos los subgrupos descriptos para cada capa los que se encuentran representados en todas las capas de nuestro muestreo son:

- los raspadores frontales de filo corto (RFFC),

- los raspadores frontales de filo extendido (RFFE) y,

- Ios filos largos (Fla) o filos complementarios (sensu Gradin et al. 1976: 236) que se asocian a los distintos subgrupos de raspadores.

Un grupo particular son los raspadores de filo restringido "en hocico" (RFFRH), que aparecen en dos de las capas. En seis de los siete casos analizados es el único filo con rastros de uso presente en la pieza (y se encuentran acompañados por filos complementarios, largos), por lo que el diseño particular de estos instrumentos nos resulta interesante de analizar aunque no se hayan recuperado raspadores de este tipo en la capa 5.

Es así como la discusión central de los resultados macroscópicos se centrará en los RFFC, RFLE, RFFE y RFFRH. Los Fla serán considerados aparte dado que la presencia de rastros complementarios, como por ejemplo microlascados discontinuos y melladuras, puede ser considerado un indicador, por ejemplo, de enmangue lo cual será evaluado más adelante en un trabajo en curso.

\section{b)Volumen y peso}

En primer lugar queremos mencionar los aspectos referidos al volumen y peso de cada uno de los subgrupos tipológicos mencionados y como esto se vincula con el tipo de sostén del instrumento al realizar la acción de uso, de acuerdo a la cinemática inferida. Resulta interesante considerar estos dos atributos complementarios (peso y volumen) para no sólo darnos una idea de cuan livianos

\begin{tabular}{lccc}
\hline $\begin{array}{c}\text { Muestra } \\
\text { estudiada }\end{array}$ & $\begin{array}{c}\text { Total } \\
\text { recuperado }\end{array}$ & $\begin{array}{c}\text { Muestra } \\
\text { seleccionada }\end{array}$ & $\begin{array}{c}\text { N luego de los } \\
\text { primeros análisis } \\
\text { microscópicos }\end{array}$ \\
\hline CAPA 4 c & 63 & 14 & 14 \\
CAPA 5 & 50 & 10 & 5 \\
CAPA 6 & 68 & 26 & 22 \\
TOTAL & 181 & 50 & 41 \\
\hline
\end{tabular}

Tabla 1. Cantidades de instrumentos recuperados y analizados por capa. 


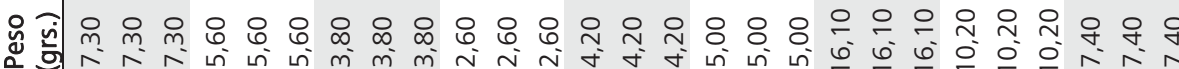

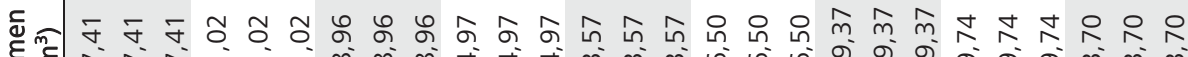

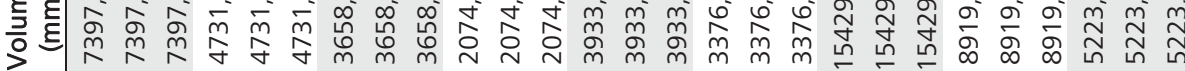

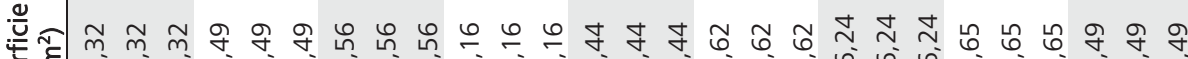

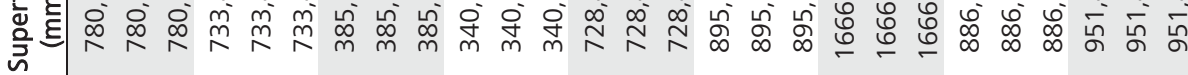
产

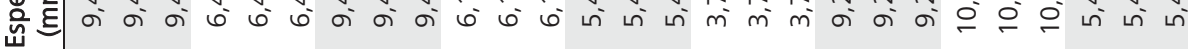
은 $\bar{\varepsilon}$ 进氙

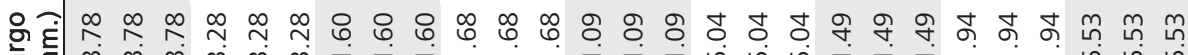

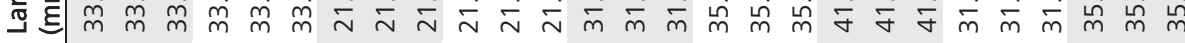
$\stackrel{-}{\circ}$

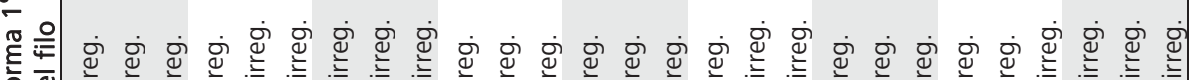

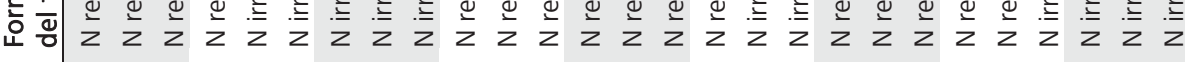
歌을 โ

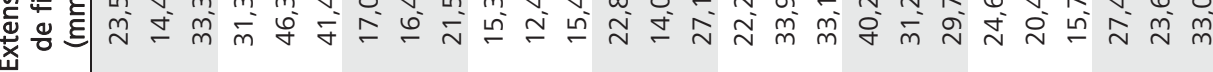

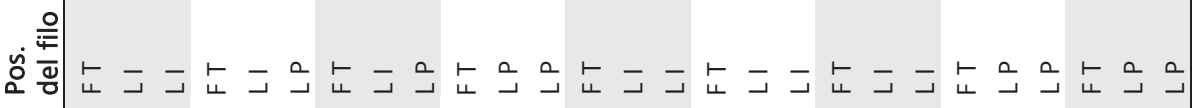

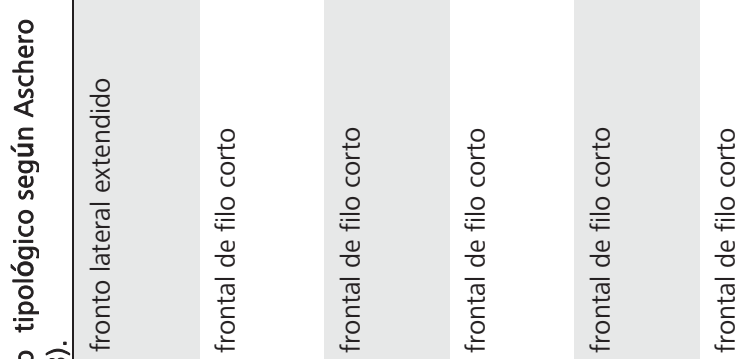

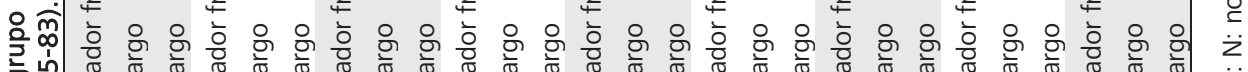

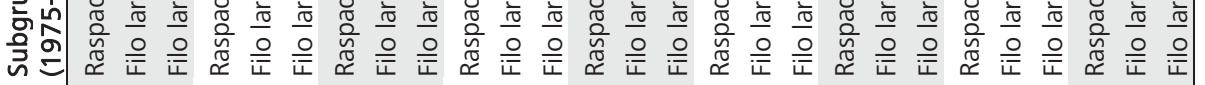

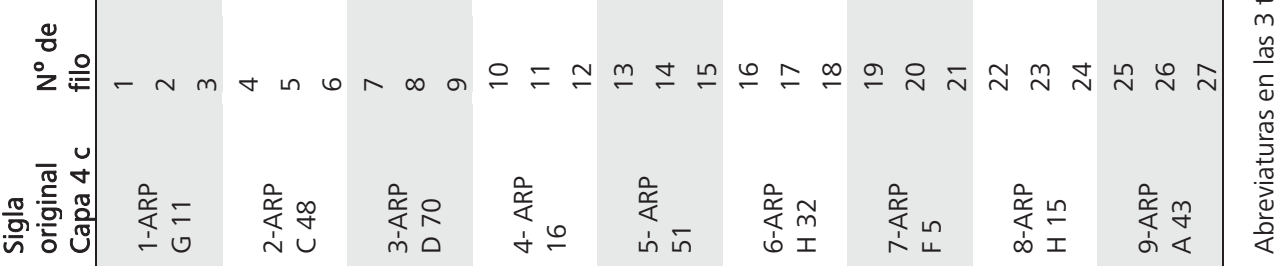

Tabla 2. Descripción de los instrumentos pertenecientes a la capa 4c de ARP1. La alternancia entre sombreado y blanco indica cambio de un instrumento a otro. 


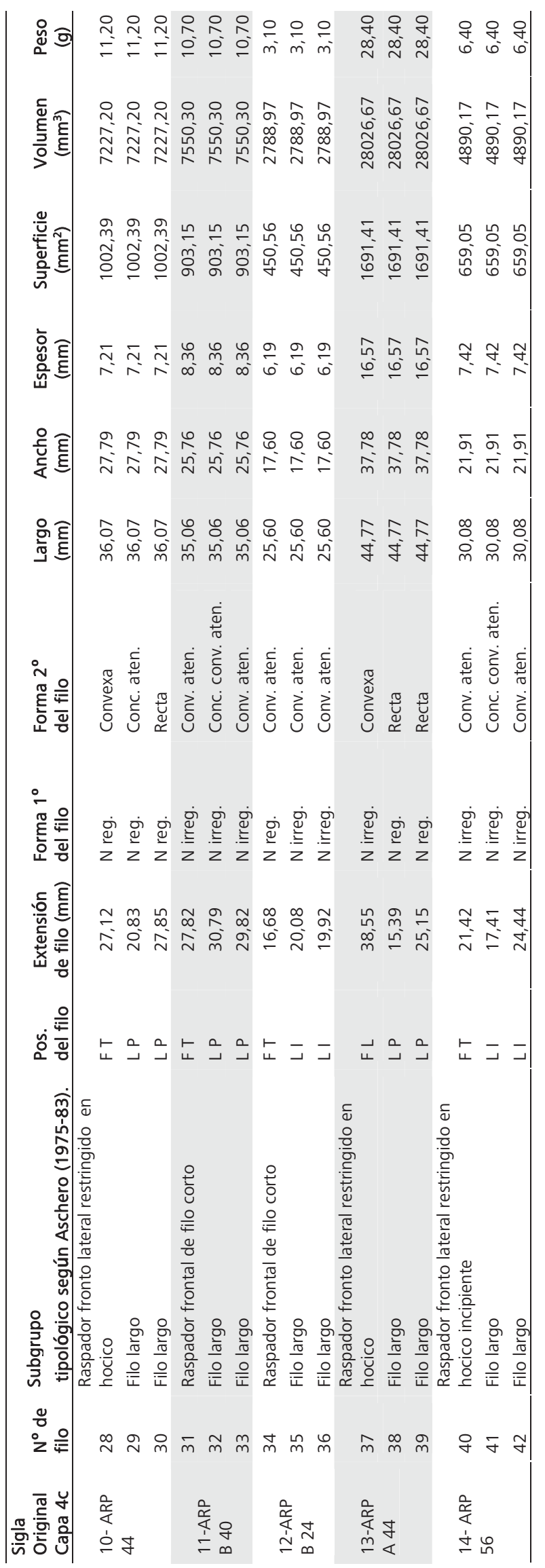

Tabla 2 (Cont.). Descripción de los instrumentos pertenecientes a la capa $4 c$ de ARP1. La alternancia entre sombreado y blanco indica cambio de un instrumento a otro.

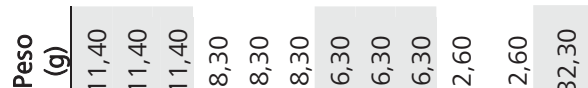

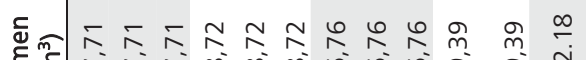

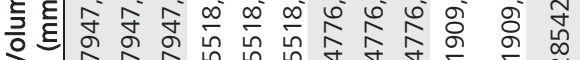

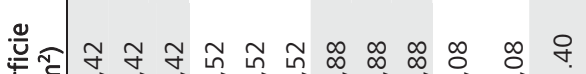

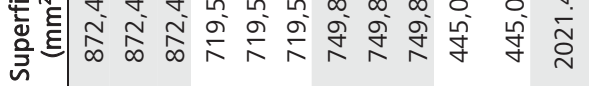

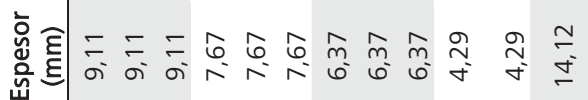

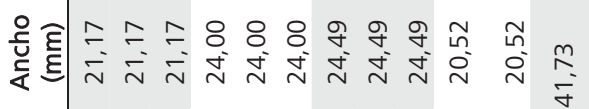

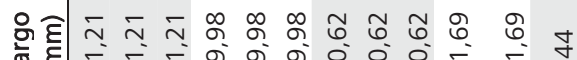

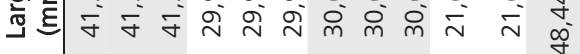

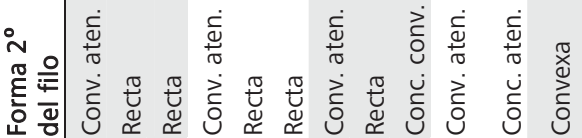
$\circ-\frac{10}{4}$

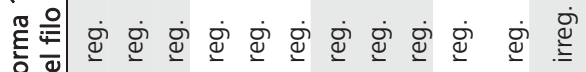

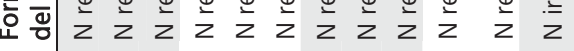

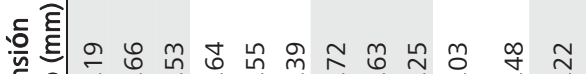

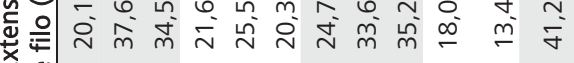
ㄸํㅁ

은 은

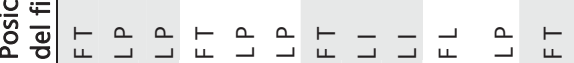

$\underset{\infty}{\dot{m}}$

กิ

$\stackrel{\circ}{\circ}$

产

窎

8.

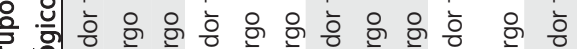

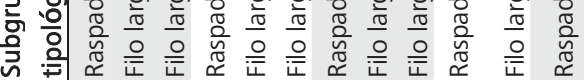

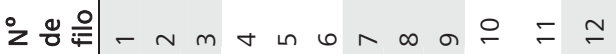

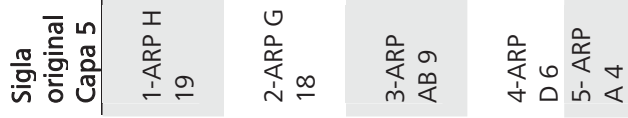

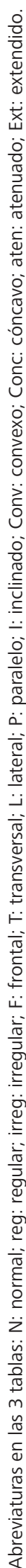

Tabla 3. Descripción de los instrumentos pertenecientes a la capa 5 de ARP1. La alternancia entre sombreado y blanco indica cambio de un instrumento a otro. 


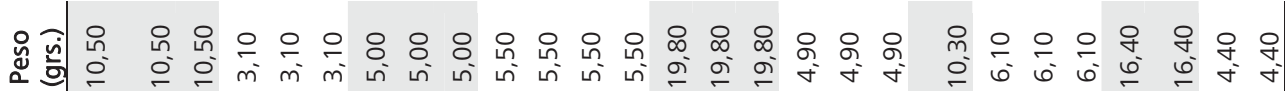

๘ >

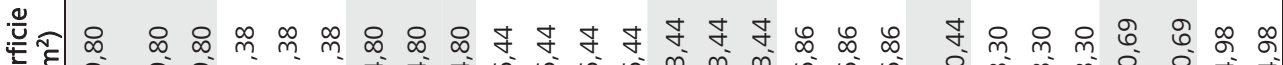

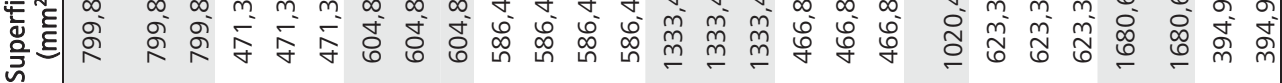

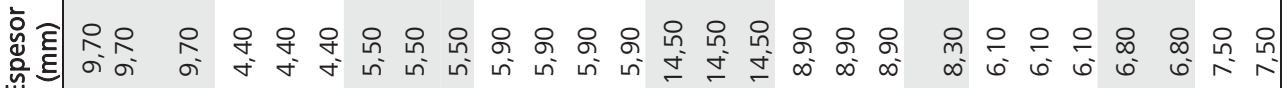

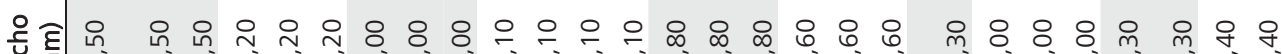

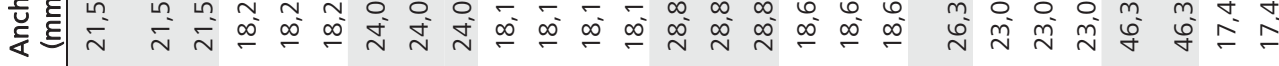

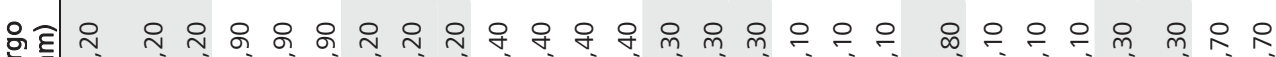

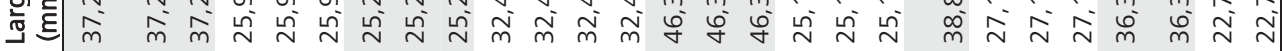

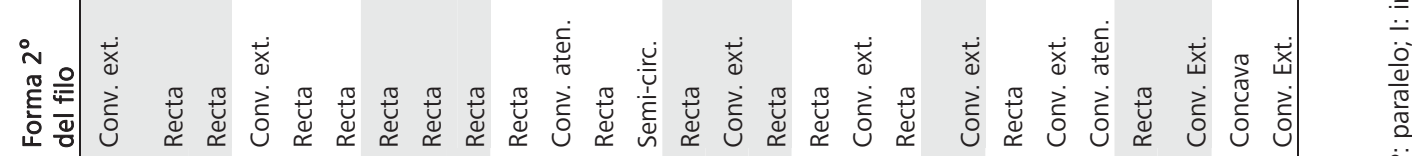

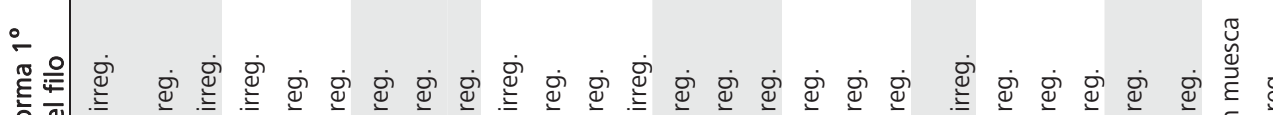

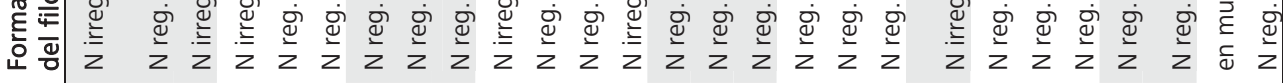

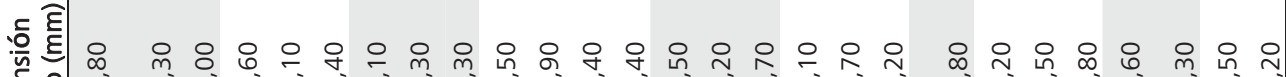
践弟焉

은 은

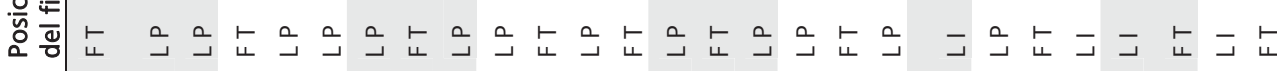

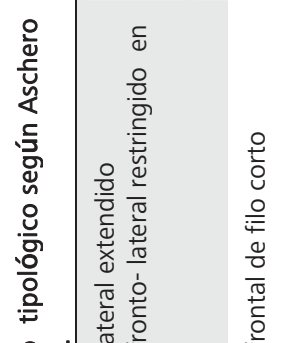

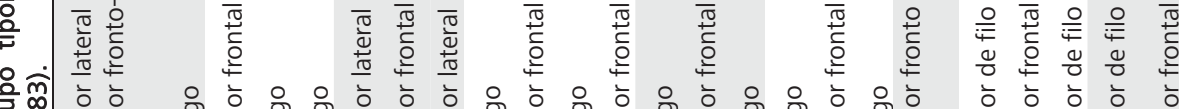

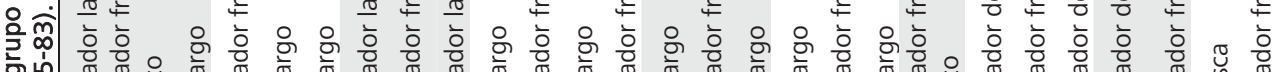

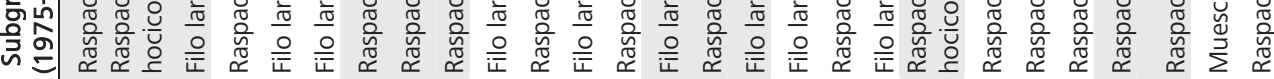

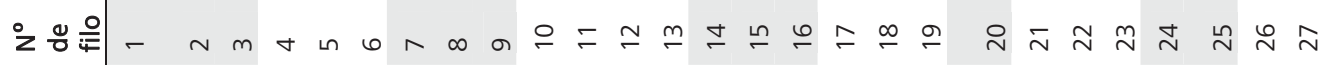

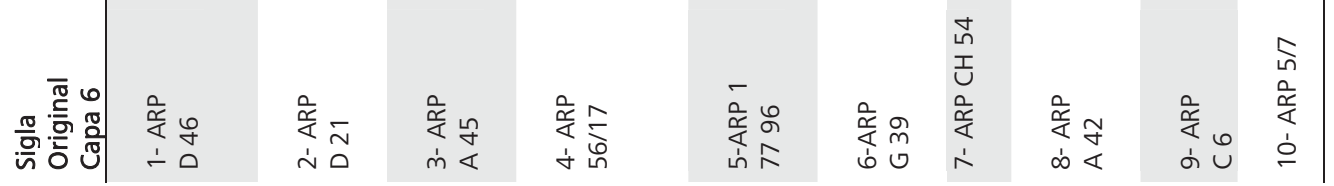




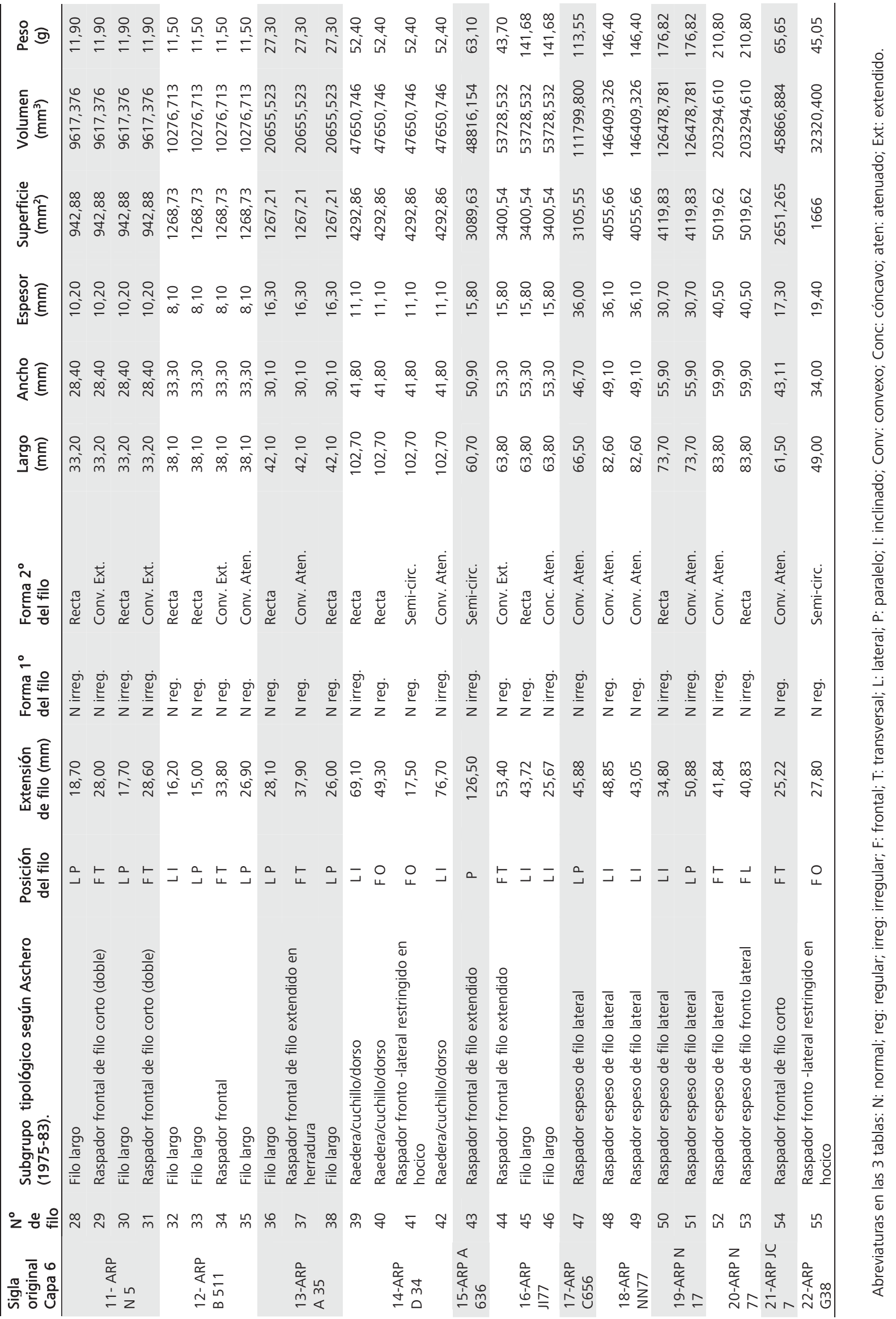

Tabla 4 (Cont.). Descripción de los instrumentos pertenecientes a la capa 6 de ARP1. La alternancia entre sombreado y blanco indica cambio de un instrumento a otro. 


\begin{tabular}{|c|c|c|c|c|c|c|c|c|c|c|c|}
\hline & RFFC & RFFE & Fla & RFFRH & RFLE & $\begin{array}{c}\text { R } \\
\text { espeso } \\
\text { de filo } \\
\text { Fy F L }\end{array}$ & $\begin{array}{c}\text { R de filo } \\
\text { lateral } \\
\text { extendido }\end{array}$ & $\begin{array}{l}\text { R de filo } \\
\text { Lateral }\end{array}$ & $\begin{array}{c}\text { Raedera } \\
\text { /cuchillo } \\
\text { /dorso }\end{array}$ & $\begin{array}{c}\text { RF en } \\
\text { herra- } \\
\text { dura }\end{array}$ & Muesca \\
\hline Capa 4c & 8 & 1 & 28 & 3 & 2 & --- & --- & --- & --- & --- & --- \\
\hline Capa 5 & 3 & 1 & 7 & --- & 1 & --- & --- & --- & --- & --- & --- \\
\hline Capa 6 & 12 & 3 & 18 & 4 & -- & 7 & 3 & 3 & 3 & 1 & 1 \\
\hline
\end{tabular}

Tabla 5. Cantidades de piezas por subgrupo tipológico de la muestra estudiada. Para los casos de piezas con varios filos combinados se consideró aquí cada filo por separado (para las combinaciones, ver Tablas 2, 3 y 4).

\begin{tabular}{|c|c|c|c|c|}
\hline & RFFC & RFLE & RFFE & RFFRH \\
\hline Capa 4c & $5,65 / 7,370,93$ & $7,35 / 5.223,70$ & $16,10 / 15.217,85$ & $15,33 / 20.072,02$ \\
\hline Capa 5 & $8,66 / 9,121,59$ & $2,60 / 1.909,39$ & $32,30 / 28.542,18$ & --- \\
\hline Capa 6 & $8,18 / 1,442,47$ & --- & $41,06 / 56.986,68$ & $24,40 / 38.479,54$ \\
\hline
\end{tabular}

Tabla 6. Peso (en gramos) y volumen (en $\mathrm{mm}^{3}$ ) promedio de cada subgrupo tipológico, por capa.

son sino también que volumen ocupan en nuestra mano, posibilitando el sostén digital, dígito-palmar o la conveniencia de un mango. Ya los autores habían advertido esta posible situación (Aguerre 1979:40).

Si analizamos el promedio de valores para los subgrupos que están presentes en las tres capas (Tabla 6) puede observarse que los mayores valores relativos al peso, se encuentran en la capa 6 . Le siguen en orden los valores de la capa 5 aunque los RFLE resultan ser los más pequeños y livianos de toda la muestra $(2,60 \mathrm{~g})$. Para la capa $4 \mathrm{c}$ se mantiene la disminución de los valores en relación a la capa 6 para todos los casos. Si en cambio nos referimos al volumen por ejemplo que los RFFC de capas 5 y 6 son de pesos similares pero que los de capa 6 son muy superiores en volumen. Es decir el tamaño tradicional (largo X ancho) es similar, pero las de capa 6 son mucho mas espesas. Lo mismo sucede con los RFFE (entre capas 5 y 6) y los RFFRH (entre capas 4c y 6) donde aunque son algo mayores de tamaño el espesor determina un volumen muchísimo mayor (para el detalle ver también las Tablas 3, 4 y 5).

\section{c) Extensión de los filos}

Otro aspecto a considerar es el referido a las variaciones en la extensión de los filos. De acuerdo al análisis de las extensiones de las áreas activas de las piezas, por capa, se registraron en los instrumentos simples ${ }^{(2)}$ los valores observados en la Tabla 7 y Figuras 3, 4 y 5.

Con respecto a los RFFC la extensión promedio ( $22 \mathrm{~mm}$ ) es prácticamente la misma en los tres momentos estudiados, con variaciones de menos de $0,5 \mathrm{~mm}$. Para el caso de los RFLE hay una mayor variación (entre 18 y 25mm) para las dos capas en la que este subgrupo esta representado.

Los RFFE tienen extensiones similares en capas 4c y 5 , casi duplicándose su extensión promedio en capa 6 ,

2 Se consideraron únicamente aquellos instrumentos de filo simple + dos filos largos que en un principio fueron denominados filos complementarios (Gradin et al. 1976) y que hoy nosotros quizás veríamos vinculados a enmangue. Para los casos de instrumentos dobles (dos casos de capa 6) se consideró que el uso de un filo imposibilitaba el uso del otro dada su posición y el enmangue probable y por lo tanto se los consideró a estos fines como instrumentos simples.

\begin{tabular}{llllll}
\hline & RFFC & RFLE & RFFE & RFFRH & Fla \\
\hline Capa 4c & 22,24 & 25,48 & 40,24 & 29,03 & 24,83 \\
Capa 5 & 22,18 & 18,03 & 41,22 & --- & 28,64 \\
Capa 6 & 22,44 & --- & 75,07 & 15,20 & 23,55 \\
\hline
\end{tabular}

Tabla 7. Promedio de extensiones de los filos (en $\mathrm{mm}$ ), por capa.

hecho surge de incluir una de las piezas de mayor peso y volumen (que originalmente fue clasificada como rabots). Si quitamos esa pieza el promedio baja a 49,35 y de todos modos son, en promedio, más largos que los de las otras capas.

El caso de los RFFRH es el que más variación presenta siendo la mitad de extensos los de capa 6 en relación a los de capa 4c.

En último término, si analizamos cómo se vinculan estos datos (subgrupo de raspador) en relación a la posición de los filos en los utensilios se observa que los filos largos son siempre laterales, mayormente paralelos para los de capa 6 y 5, mientras que en capa 4c se reparten equilibradamente los de tipo lateral inclinado y paralelo en relación al eje longitudinal de la pieza.

Si analizamos las extensiones de los filos largos (Fla) vemos que en promedio no sobrepasan a las extensiones de los filos cortos en 2 o $3 \mathrm{~mm}$. En capa 5 se registraron las mayores variaciones, con un promedio de $28 \mathrm{~mm}$.

En la actualidad el estudio de estos filos largos es objeto de una investigación derivada para tratar de establecer su uso en relación a un enmangue probable (Cattáneo 2009, en preparación).

\section{Análisis funcionales de base microscópica.}

Como ya se mencionó, se analizaron 41 instrumentos desde el punto de vista funcional comparando las imágenes de los filos arqueológicos obtenidas con el CLSM con las de la base de datos experimentales. Dicha base de datos fue conformada por más de 600 imágenes de filos líticos que trabajaron distintas materias primas durante diferentes cantidades de tiempo.

Los instrumentos experimentales eran de rocas altamente silicificadas, como tobas vítreas, jaspes y ópalos. Para un 


\begin{tabular}{lcccc}
\hline \multicolumn{1}{c}{ Capa 4c } & RFFC & RFLE & RFFRH & RFFe \\
\hline Vegetales no leñosos & $3,4,5,6,8$ & 9 & 10 & 7 \\
Combina vegetales no leñosos y hueso en estado seco & 11,12 & - & 13,14 & - \\
Hueso en estado seco y cuero seco sin piel & - & 1 & - & - \\
Material duro, probablemente hueso & 2 & - & - & - \\
\hline
\end{tabular}

Tabla 8. Determinación probable de materias primas trabajadas para los filos de raspadores de capa 4c. El número corresponde al número de pieza en la tabla 4.

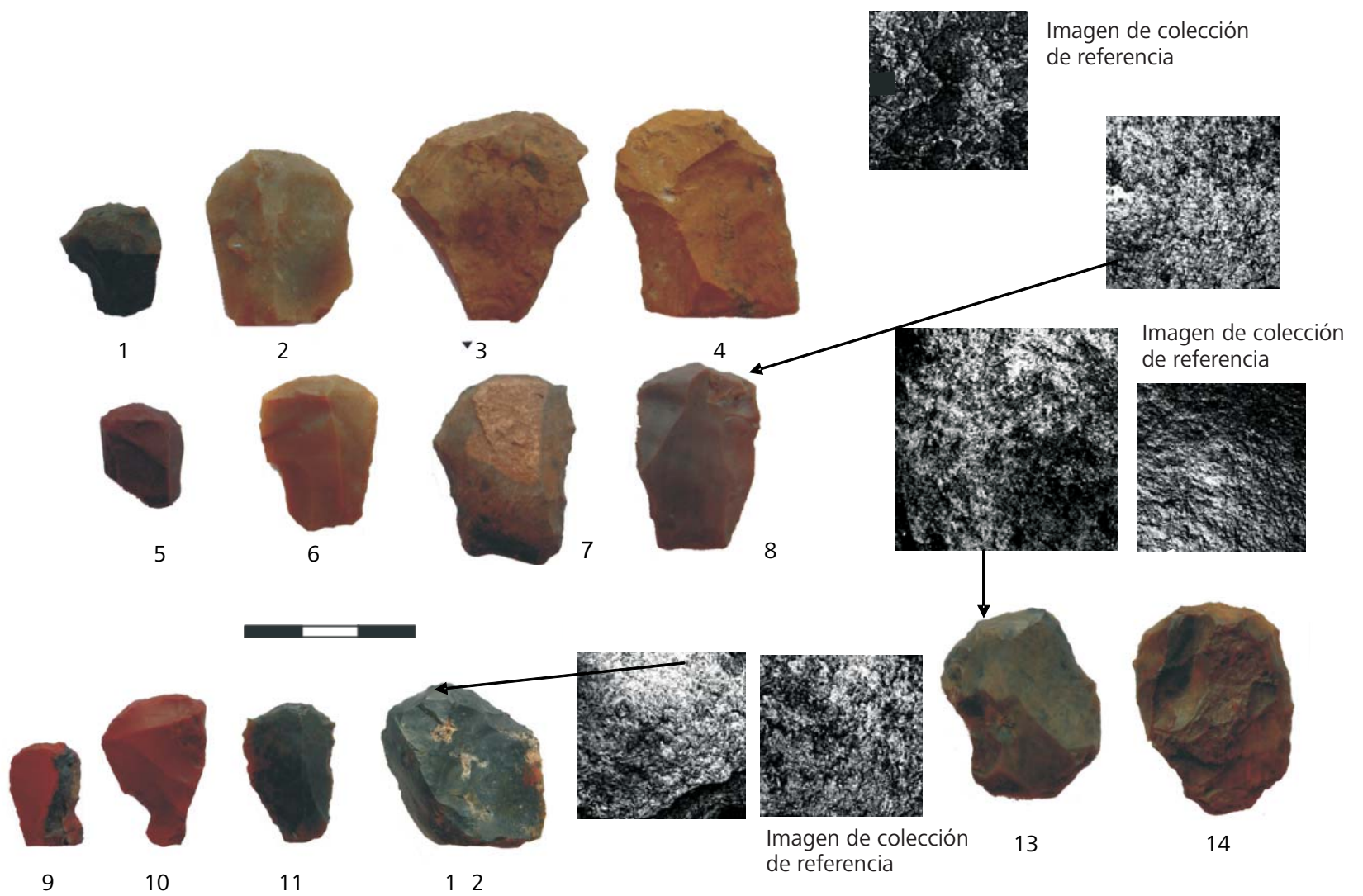

Figura 4. Muestra de raspadores de ARP1, capa 4c. 1 a 8: corresponden a RFFE o RFFC utilizados para el raspado de maderas no leñosas (Nombre de las piezas en Tabla 2=1:D70, 2:H15, 3:F5, 4:44, 5:16, 6:51, 7: A43 y 8:H32). Casos 9 a 12: RFL, RFFC y en hocico utilizados para el raspado de hueso seco. (Nombre de las piezas en Tabla 2= 9:B24 10: G11, 11:C48, y 12: A44). 13 y 14: Raspadores que combinaron el trabajo transversal sobre madera y hueso (Nombre de las piezas en Tabla $2=13: 56$ y 14: B46). Las imágenes fueron obtenidas a 100X.

detalle de los procedimientos de comparación de imágenes, (que utilizan la distancia Euclidiana de las matrices de co-ocurrencia de cada imagen) puede verse Cattáneo et al. (2007b) donde se explica el desarrollo y el funcionamiento del paquete de programas PHILOS.

Las imágenes relevadas de los 109 filos arqueológicos, y su comparación posterior utilizando PHILOS permitieron establecer, en ciertos casos, micropulidos diagnósticos originados por el trabajo de distinto tipo de materiales en distintas situaciones topográficas.

En trabajos experimentales previos (Cattáneo et al. 2007b) a través del uso del software de reconocimiento de micropulidos, se determinó que era posible clasificar imágenes provenientes de tratamiento de huesos secos y vegetales leñosos (madera) con, un 80 a 85\% de certeza. Además, las características de cada grupo de imágenes permitían separarlas entre sí, sin posibilidades de error, y esto nos permitió en algunos casos determinar que ciertos instrumentos trabajaron más de una materia prima.
Para el conjunto de 109 filos en líneas generales se registraron las acciones de raspado de tres tipos de materiales: materiales vegetales leñosos y no leñosos, huesos tanto secos como frescos, y cueros sin piel, en estado fresco y $\operatorname{seco}^{(3)}$

\footnotetext{
3 Por materiales vegetales leñosos entendemos aquellos que presentan un alto grado de dureza debido a su composición con alto contenido de duramen, corteza y fibras (por ej. madera de Nothofagus sp.) a diferencia de los materiales vegetales no leñosos, como pastos e hierbas sin estructura de sostén, como Stipa sp., Fabiana sp. o ramas verdes de Berberis sp. También existen procedimientos, como el estacionado o uso de fuego para incrementar la dureza y/o resistencia de las distintas especies. Con respecto a los huesos, la experimentación ha demostrado las diferencias notables entre los micropulidos producto del raspado de huesos frescos y de huesos en estado seco, cuando han perdido no sólo la humedad sino sobre todo la gratitud del periostio, que actúa por ej. dificultando las tareas de raspado y embotando rápidamente los filos (por ej. con Lama guanicoe). Con respecto al tratamiento de cueros, con y sin piel, y/o frescos o en estado seco, al igual que en los huesos de esta especie, las diferencias notables en la fricción en húmedo o en seco generan superficies notoriamente diferentes. Para un detalle de estas diferencias ver Keeley (1980) y bibliografía allí citada.
} 


\begin{tabular}{lccc}
\hline \multicolumn{1}{c}{ Capa 5 } & RFFC & RFLE & RFFE \\
\hline Veaetales leñosos & $1,2,3$ & - & - \\
Vegetales no leñosos & - & - & 4 \\
Combina vegetales leñosos y no leñosos & - & 5 & - \\
\hline
\end{tabular}

Tabla 9. Determinación probable de materias primas trabajadas para los filos de raspadores de capa 5 . El $n^{\circ}$ corresponde al $n^{\circ}$ de pieza en la tabla 3.

En el análisis de los filos de los instrumentos de capa 4c, en alrededor de un $60 \%$ se registró la acción de raspado de maderas blandas (Figura 4: casos 1 a 8) correspondiendo tanto a RFFC como a RFFE. Un 25\% trabajó en acción transversal sobre huesos secos (Figura 4: casos 9 a 12, RFFC, RFL y en hocico). El resto, un 15\%, combinó el trabajo de ambos materiales (Figura 4: casos 13 y 14).

Para el caso del análisis de microhuellas de las aristas activas de los raspadores de capa 5 únicamente se registró acción transversal sobre maderas leñosas (Figura 5: casos 1 a 3, todos RFFC) y no leñosas (Figura 5: casos 4 y 5, un RFFC y un RFL).

Del total de los instrumentos de la capa 6, sobre un total de 54 filos analizados en 21 piezas (Figura 6: casos 1 a 17 y Figura 7: casos 1 a 5), un 40\% de los mismos registraron exclusivamente trabajo de vegetales leñosos: predominantemente aquellos con filos extendidos (Figura 7: casos 1,2 y 3) o espesos (Figura 7: casos 6 y 14). En cuatro casos (Figura 7: piezas 4, 5, 8 y 15) se interpretó el raspado de hueso en estado seco como trabajo predominante a lo largo de toda la arista. Sin embargo, estas mismas piezas presentaron imágenes comparables al trabajo de vegetales no leñosos en otros sectores estudiados.

Para el caso de las piezas 7, 11 y 16 (Figura 7) hubo predominancia de trabajo de hueso seco y también en sectores acotados el raspado de vegetales blandos. Para el caso de las piezas 9, 12, y 13 (Figura 7) se produjo una alta consistencia con trabajo de vegetales no leñosos. Sólo se registró un caso (Figura 7: 17) de trabajo de cuero en estado seco en el raspador más pequeño y liviano de la muestra.

Resumiendo, si al total de la muestra de raspadores de capa 6 (Figura 7: 1 a 5, y Figura 8) le agregamos los raspadores espesos el resultado es que totalizando 21 piezas, como dijimos anteriormente con 54 filos analizados:

- un 32\% trabajaron sobre un solo material

- un $68 \%$ combinó dos materiales. De ellos uno siempre fue vegetal (no leñoso) como uso principal y el otro era variable, mayormente hueso en estado seco (60\%) y minoritariamente cuero en estado fresco.

\section{Discusión sobre los instrumentos analizados en las tres capas}

Primero vamos a considerar el aspecto métrico en la discusión de los subgrupos tipológicos (RFFC, RFL, RFFE) que se encuentran representados diacrónicamente. Es el que se refiere a las diferencias de tamaño en relación a las extensiones de los filos, y cómo esa relación puede o no verse afectada por el sistema de sostén.

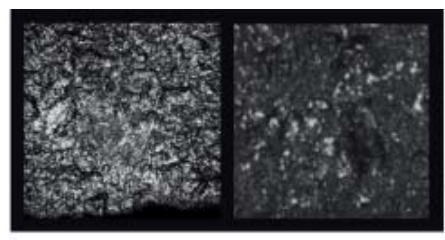

Imágenes de referencia de colecciones experimentales

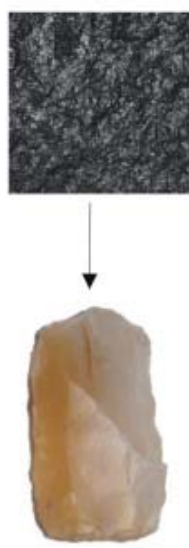

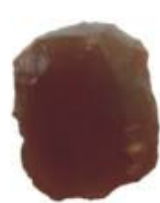

2
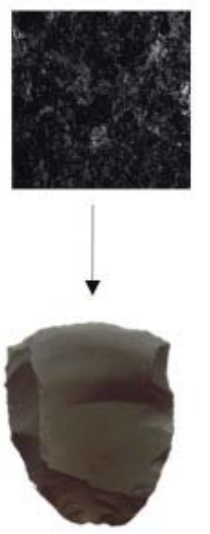

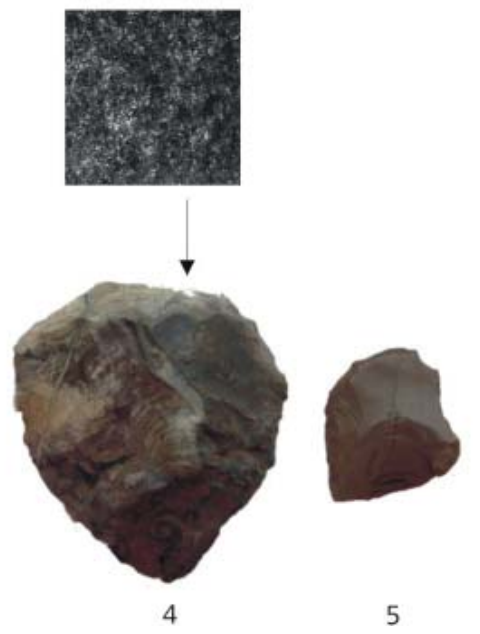

5

Figura 5. Muestra de raspadores provenientes de ARP1, capa 5: 1 a 3: raspadores frontales de filo corto con evidencia de raspado de maderas leñosas. (Nombre de las piezas en Tabla 3= 1: H19, 2: G18, Y 3: AB9). 4: raspador frontal de filo extendido. 5: raspador fronto-lateral extendido. 4 y 5 con evidencias de raspado de vegetales no leñosos (Nombre de las piezas en Tabla 3=4: A4, y 5:D6). Las imágenes están tomadas a $100 X$. 
En primer lugar, se observa una estandarización muy marcada en los grupos de RFFC, especialmente en cuanto al peso. Para los momentos más tempranos, en las capas 5 y 6 si se observa la Tabla 6 se verá que varían en menos de $0,5 \mathrm{~g}$. Con respecto a la capa $4 \mathrm{c}$ varían en promedio en alrededor de $2 \mathrm{~g}$.

No sucede lo mismo con respecto al volumen que si bien es similar entre las capas 4c y 5 aumenta a más del doble. Pero debemos ser cautelosos con este promedio en particular dado que se incluyó en este subgrupo una pieza que por su espesor había sido considerada previamente como un posible cepillo (ver Figura 7b para una idea del volumen).

Por otro lado si consideramos aquellos raspadores de filos extendidos (RFFE) Gradin et al. (1976) y Aguerre (1977) ya observaron una disminución en el tamaño a través del tiempo. Son llamativos, en este último caso, las similitudes de diseño entre tres raspadores, provenientes uno de cada capa (Figura 9). Ahora bien, pese a esa disminución de tamaño, por ejemplo en capa 5, si comparamos con capa 4c se observará la similitud en las extensiones de los filos pero el promedio el peso y tamaño de las piezas estudiadas es mayor en capa 5. Si comparamos con capa
6, son menores las extensiones, el peso y tamaño.

El aspecto que resulta interesante destacar es que pese a las variaciones de tamaño se sigue manteniendo a través del tiempo la extensión de los filos. Este aspecto podría estar señalando dos cosas: por un lado que hay variaciones en el sistema de sostén (que pueden ser distintos sistemas o, por ejemplo, distintos tamaños de manos); por el otro, que la actividad a desarrollar podría estar muy estandarizada dado lo preciso del largo de los filos.

\section{Apreciaciones finales}

Mencionaremos brevemente los contextos en los cuales fueron recuperados los instrumentos estudiados, luego sus asignaciones funcionales y finalmente la relación entre dicha asignación y su diseño.

Es así como desde la perspectiva funcional pudimos detectar el uso de los raspadores para el trabajo de vegetales leñosos (madera), huesos en estados diversos y minoritariamente cueros sin pelo.

En la capa 4c se interpretó la existencia de un basural donde se recuperaron una variedad de instrumentales

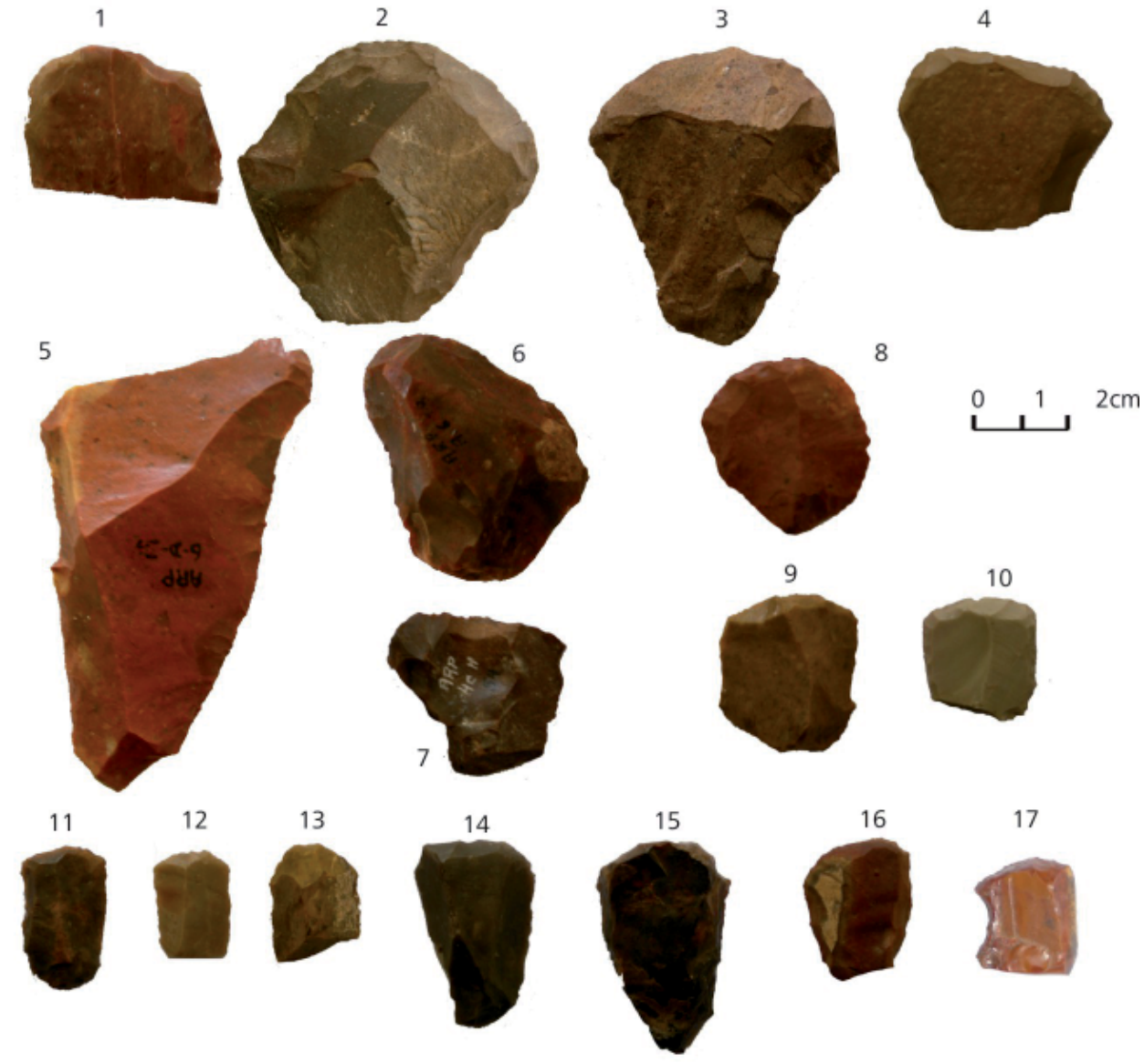

Figura 6. Raspadores analizados provenientes de ARP1 capa 6: 1 a 4: Raspadores de filo extendido. 5 a 7: Raspadores de filo restringido, en hocico. 8: Raspador de filo extendido "en herradura". 9-10: Raspadores dobles. 11 a 13: Raspadores frontales de filo corto, pequeños. 14 a 17: Raspadores frontales de filo corto, medianos. (Nombre de las piezas en Tabla 4=1: A35, 2: A636, 3: J177, 4: C6, 5: D34, 6:G38, 7:CH54, 8:B511, 9:N5, 10: A45, 11:56/17, 12:D21, 13:G39, 14:D46, 15:7796, 16:A42, y 17:5/7). 
Actividad de raspado sobre vegetales no leñosos y cuero en estado fresco
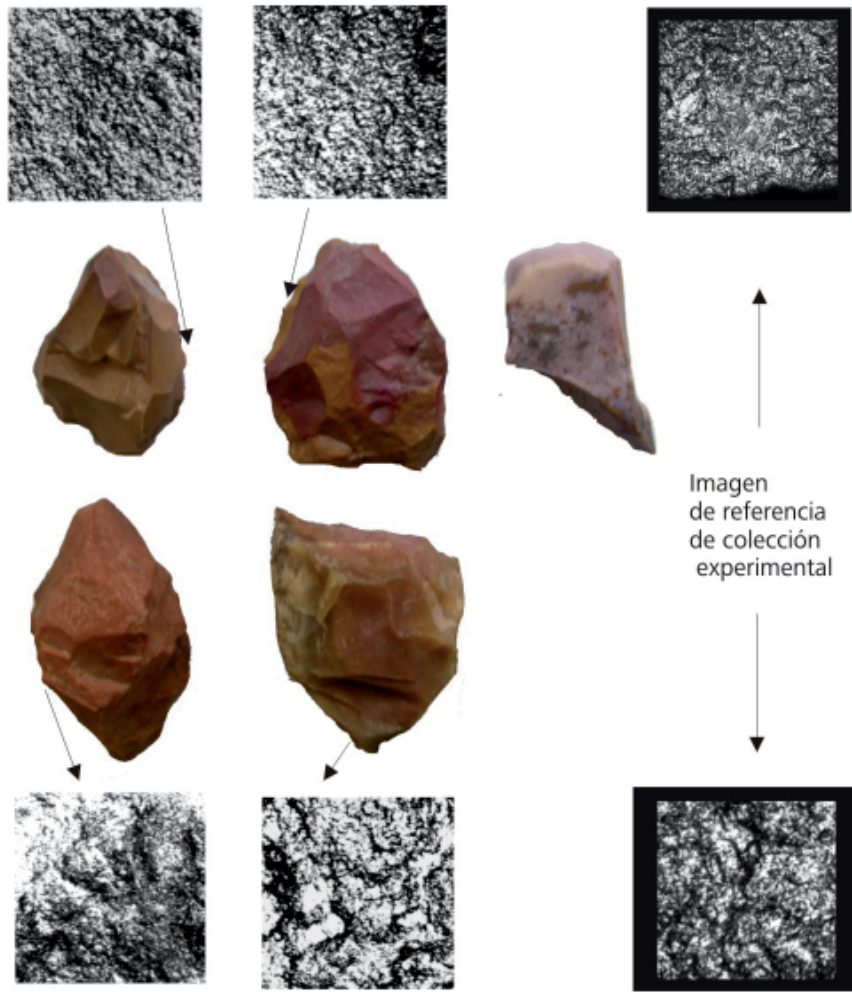
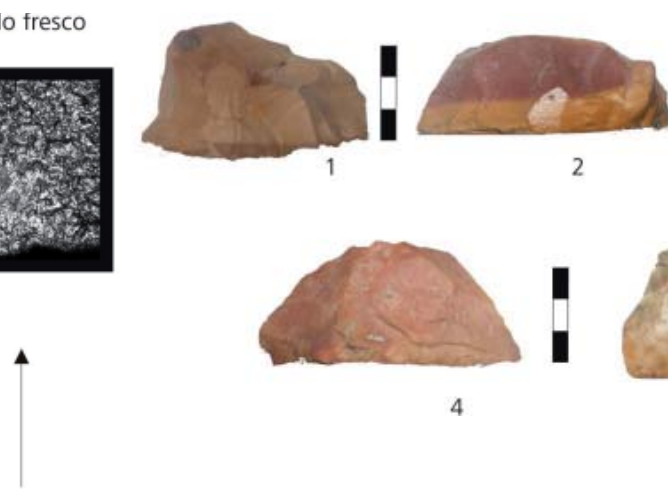

2
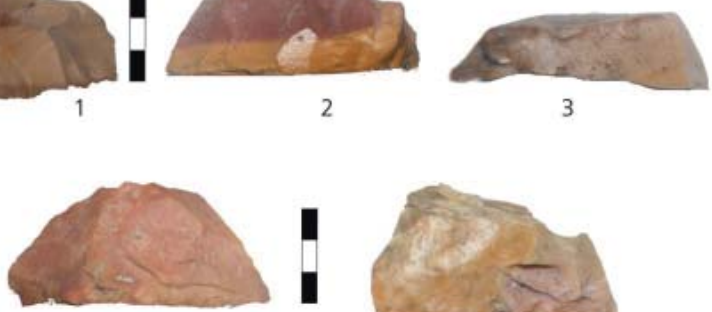

4

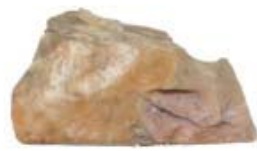

5

Imagen

de referencia

de colección

experimental

Figura 7a.(Izquierda) Ejemplo de raspadores espesos de ARP1, capa 6, e imágenes de micropulidos a 100X sobre aristas activas e imágenes de las colecciones de referencia utilizadas.

Figura 7b.(Arriba derecha) Obsérvese los espesores de las piezas. Nombre de las piezas en Tabla $4=1$ : C656, 2:N17, 3:JC7, 4:NN77 Y 5:N77.

\begin{tabular}{|c|c|c|c|c|c|c|c|c|}
\hline Capa 6 & RFFC & RFLE & RFFE & $\begin{array}{l}\text { R espeso } \\
\text { de filo } \\
\text { Fy F L }\end{array}$ & $\begin{array}{l}\text { Raedera/ } \\
\text { cuchillo/ } \\
\text { dorso }\end{array}$ & $\begin{array}{l}\text { R de filo } \\
\text { lateral } \\
\text { extendido }\end{array}$ & $\begin{array}{l}\text { RFFR } \\
\text { Herradura }\end{array}$ & $\begin{array}{l}\text { RFFR en } \\
\text { hocico }\end{array}$ \\
\hline $\begin{array}{l}\text { Vegetales no leñosos } \\
\text { exclusivamente }\end{array}$ & $9(2)$ & - & 2,3 & - & - & 14 & 1 & 6,14 \\
\hline $\begin{array}{l}\text { Hueso en estado seco y } \\
\text { secundariamente } \\
\text { vegetales no leñosos }\end{array}$ & $4,8,16$ & $16(2)$ & 4 & - & $5(3)$ & - & - & 5 \\
\hline $\begin{array}{l}\text { Vegetales no leñosos y } \\
\text { cuero en estado fresco }\end{array}$ & - & - & & $\begin{array}{l}\text { Fig } 7: \\
1 \text { a } 5\end{array}$ & - & - & - & - \\
\hline $\begin{array}{l}\text { Vegetales no leñosos y } \\
\text { hueso en estado seco }\end{array}$ & $\begin{array}{c}11(2) \\
12,13,15\end{array}$ & - & & - & - & - & - & - \\
\hline Cuero & 17 & - & & - & - & - & - & - \\
\hline Hueso en estado seco & 10 & - & & - & - & $10(2)$ & - & 7 \\
\hline
\end{tabular}

Tabla 10. Determinación probable de materias primas trabajadas para los filos de raspadores de capa 6 . El número corresponde al número de pieza en la Figura 6, sino, se aclara a que figura corresponde. Entre paréntesis las cantidades de filos con esa asignación a material trabajado.

Figura 8. Ejemplos de microhuellas de utilización en algunos de los casos de capa 6. Las imágenes fueron tomadas a 100x. 1 al 5: Acción de raspado sobre vegetales no leñosos exclusivamente.

6 al 9: Acción de raspado sobre hueso seco
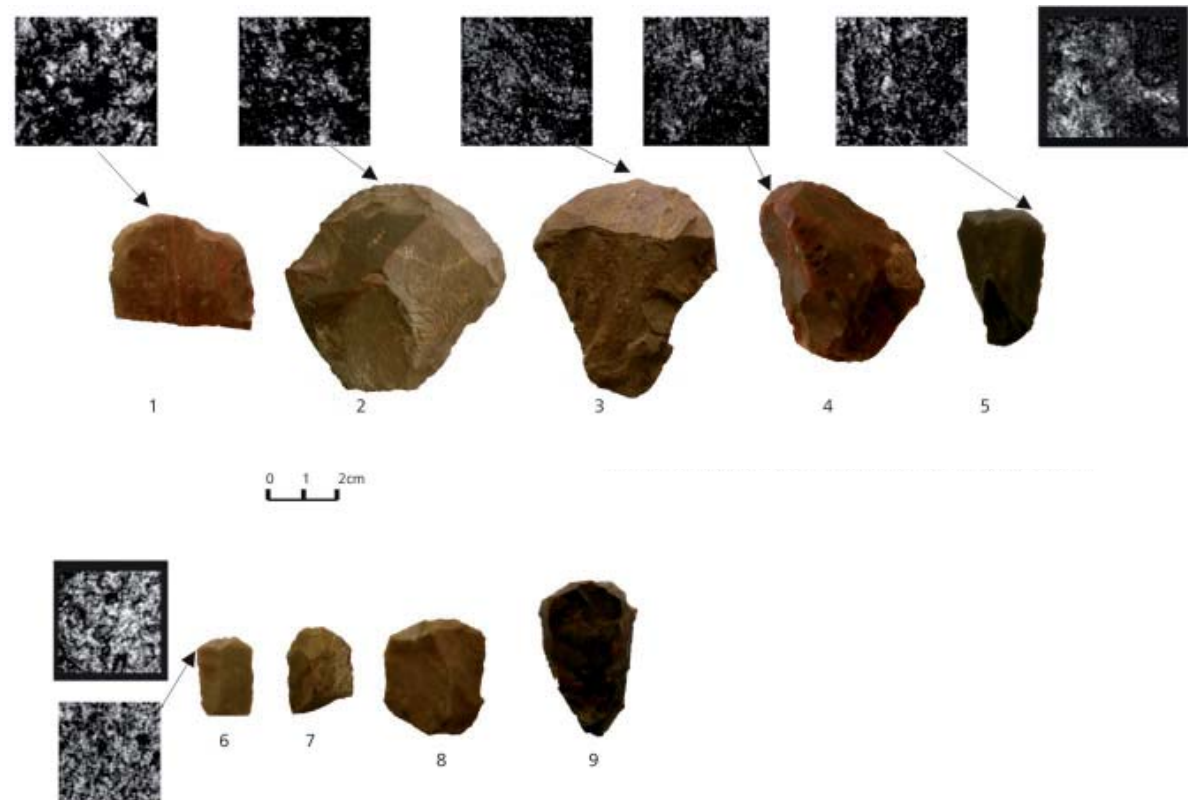


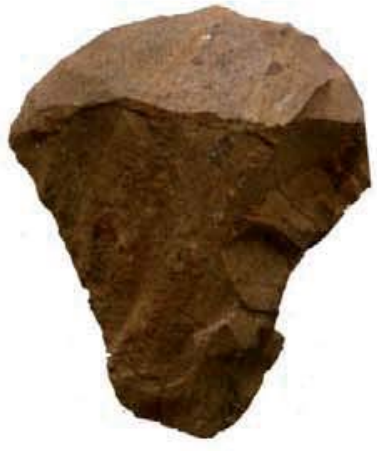

1 Capa 6

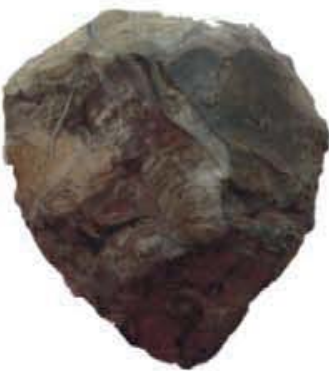

2 Capa 5

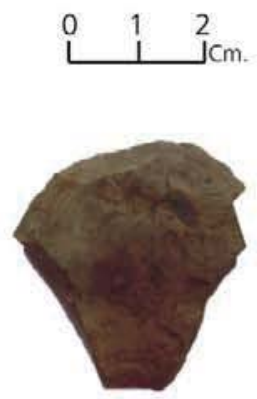

3 Capa 4c

Figura 9. Raspadores frontales de filo extendido pertenecientes a capas 6, 5 y 4c. Nótese la similitud en la extensión del filo y la diferencia de tamaño.

óseos: entre ellos una escápula de Lama sp. con arista pulida y marcas de cortes transversales y oblicuas en ambas caras, fragmentos de húmero con filos naturales y lascados de uso, otro húmero recortado en forma oval con marcas de percusión y corte, dos fragmentos de diáfisis con retoques sumarios, una muesca retocada con la arista del filo semi-pulida por utilización, un fragmento de diáfisis formatizado por pulido, con acanaladura en la cara interna y estrías transversales sobre los bordes de la misma (Gradin et al. 1976:233, figura 22), un fragmento de punzón y una cuenta elíptica de hueso con orificio de sección bicónica y estrías sobre una de las caras (Gradin et al. 1976: figura 14 de página 233). También se recuperaron allí tres instrumentos de madera con extremos aguzados semejantes a punzones, de sección sub-circular (Gradin et al. 1976: 235). Para la capa 4c los autores destacan la recuperación de fragmentos de piel de guanaco y de manojos de pelos o vellones, por lo que fue planteada la posibilidad de la tarea de pelado de pieles en el lugar (Gradin et al. 1976:235).

Asimismo, en la capa 5 estos autores mencionan la presencia de dos artefactos en hueso. Por un lado un tubo de hueso con su superficie externa e interna fuertemente pulida y por fuera ligeramente facetado y con bordes romos y estrías. Además recuperaron un fragmento de hueso con incisiones de sección plana y bordes romos, presentando una de sus caras numerosos trazos rectos. También se recuperó pelo de animal y plumas (Gradin et al. 1976: 229, figuras 9 y 10 y 230). Acá tenemos un tema igual de interesante, se trata de un tubo de hueso seco al que los autores ven pulido con los bordes romos. Nos interesará también en un futuro analizar las diferencias en los procesos de manufactura entre un pulido e incisiones en hueso seco o fresco.

Entre los materiales recuperados en los contextos de la capa 6 los autores describen dos punzones, uno al que también se lo definió como punzón con punta fusiforme alargada sobre diáfisis indeterminada, con una porción proximal troncocónica de base plana y sección transversal circular, en parte rebajada interesando el tejido esponjoso con incisiones decorativas y otro punzón hecho sobre una diáfisis de ave; además un retocador de punta roma y otro muy pulido hecho sobre una astilla de hueso. Por otra parte se recuperaron fragmentos de madera seccionados con incisiones, transversales y oblicuas y palos con aguzamientos (Gradin et al. 1976:223 y figuras 1 a 4 en Pág. 225; Gradin et al. 1979: 207). Es decir, tenemos evidencias artefactuales del uso del hueso o la madera y la decoración incisa como un plus de información. Nos debemos y está dentro de nuestra futura agenda de trabajo el poder observar estos artefactos en hueso o madera con incisiones con nuestra metodología actual. Sobre la base de los hallazgos arqueológicos de esta capa los autores (Gradin et al. 1976: 247) habían interpretado que las actividades llevadas a cabo en la cueva en el nivel inferior o más temprano, se encontraban ligadas al descarne, preparación e ingestión de los cuartos de guanaco traídos al sitio y la utilización de la médula y la preparación de cueros. En este trabajo, sobre la base del análisis funcional de los raspadores en particular, se podría además suponer el uso de los mismos para el raspado de maderas y huesos.

Sintetizando, en torno a la relación: diseño / análisis funcional, desde el punto de vista diacrónico

1. Hay raspadores que se utilizan para realizar actividades de raspado de un solo tipo de material y otros, para al menos más de una.

2. Para los casos de trabajo de un sólo tipo de material se observa: para el raspado de vegetales leñosos y no leñosos (e.g. las ramas o palillos aguzados como los recuperados en la capa 4c), raspadores con filos muy extendidos, grandes, aunque de poco espesor.

3. En Gradin et al. (1976:237) se propuso que: "La presencia de aristas pulidas y de biseles superiores a los $95 / 100^{\circ}$ sugieren particularmente el "sobado de cueros", de lo que hay indicios en la capa". Aquí hemos establecido que para el caso de raspado de cuero (escasos en la muestra estudiada) o hueso, los filos son cortos, los raspadores muy livianos (5 g) y a veces no presentan posibilidades de enmangue (Figura 5:17). Si consideramos los raspadores espesos, cuyo uso combinaba vegetales y cuero, son los más pesados y grandes del conjunto en la capa 6. Estarían 
ausentes en las otras capas.

4. Si bien deberá comprobarse la tendencia estudiando una muestra mayor, para el caso de los raspadores utilizados para trabajar más de una materia prima, si la combinación es madera y hueso: las formas y/o los tamaños son muy variables. Si la combinación es trabajo sobre madera y cuero: están muy estandarizados, son de filos rectos, largos, y las piezas más pesadas del conjunto (140 g). Las mismas presentan rasgos morfológicos que nos sugieren que han sido utilizados mediante la prehensión dígito-palmar.

5. Si bien los instrumentos de las distintas capas muestran una disminución en los tamaños a través del tiempo, si pensamos que los filos complementarios mantienen su extensión, esto podría vincularse a un sistema de sostén determinado. El punto anterior podría estar sugiriendo un tipo de sistema de sostén similar para los tres momentos y subgrupos tipológicos estudiados. Un próximo estudio de estos filos largos que se encuentra en desarrollo podrá confirmar o no esta observación.

6. En la capa 6 se observa una mayor variabilidad tipológica y funcional, pero habría que ampliar la muestra de la capa 4c (y sumar muestras de otros sitios del área), ya que podrían existir problemas de muestreo intrasitio o deberse a una variación en la funcionalidad de los asentamientos (o en diferencias de la organización intrasitio de las áreas de actividades para los distintos momentos/ capas considerados). Sin embargo, y hasta el momento, los raspadores espesos que se dieron en un número importante en la capa inferior o capa 6 y donde se registró el raspado de cueros, no vuelven a darse posteriormente, esto podría estar indicando la ausencia de esta actividad en el sitio o por ejemplo, un cambio en la modalidad del tratamiento de los cueros. El estudio de una muestra más amplia podría echar luz sobre este tema.

7. Hay otros indicios para seguir explorando, por ejemplo para el caso de RFFC en capa 6 y 4c combinan el uso para el raspado de vegetales y huesos. En la capa 5 sólo trabajaron sobre vegetales.

8. Ya había sido planteado que a través del tiempo hay una disminución en la variedad de subgrupos tipológicos por lo que lo esperable es que la utilización de cada uno de ellos en los momentos se refiera a una tarea en particular y que luego al incrementarse la estandarización, tal como es planteado en Gradin et al. (1976), la disminución de las variedades presentes este representando de alguna manera el paso a la multifuncionalidad de una clase de artefactos. El análisis de microhuellas en las diversas clases presentó evidencias de acciones similares para las tres capas: acciones transversales sobre vegetales no leñosos, seguidas de hueso en estado seco y maderas.

Como palabras finales sólo cabe agregar que estos pri- meros aportes para el área del Pinturas, son el inicio de un camino que esperamos continuar y compartir con los resultados obtenidos en localidades cercanas, por ejemplo lo realizado ya en la Altiplanicie Central para la cueva 2 de Los Toldos (Cardich, et al. 1994) o con metodologías más tradicionales en otros sitios (Aguerre 2003:51-57, Durán 1990:137-150, Guraieb 2008:131) que permitirán contrastar lo realizado, para ampliar un panorama poco explorado hasta ahora en las investigaciones del norte de la provincia de Santa Cruz.

Córdoba y Buenos Aires, Mayo de 2009.

\section{Agradecimientos}

Al Lic. Carlos A. Aschero (CONICET/UNT) quien sugirió y alentó el inicio del Proyecto de una de nosotras (GRC). A la Lic. en Geoquímica Claudia Di Lello (CIC Prov. Bs. As. (UNLP), por la determinación de las materias primas de los instrumentos aquí estudiados), a la Lic. Marilin Calo (CONICET-UBA, por la determinación de las especies vegetales recuperadas en capa). al Dr. Mario Garavaglia y los Sres. Pablo Meilán, Damián Gulich y Nahuel Lofeudo (desarrollo y aplicación del programa PHILOS). A la Lic. Gabriela Guraieb y el Dr. Jorge Martínez por la cuidadosa revisión y aportes para mejorar nuestro trabajo. A Carlos Gradin $(\mathrm{H})$ por la corrección del abstract.

\section{Bibliografía}

Anderson, P. C., J. Chabot y A. van Gijn. 2004. The Functional Riddle of Glossy Canaanean Blades and the Near Eastern Threshing Sledge. Journal of Mediterranean Archaeology 17(1): 87-130.

Aguerre, A. M. 1977. A propósito de un nuevo fechado radiocarbónico para la Cueva de Las Manos (Santa Cruz). Relaciones de la Sociedad Argentina de Antropología XI (NS): 129-142. Buenos Aires, Argentina.

Aguerre, A. M. 1979. Observaciones sobre la industria Toldense. Sapiens 3: 35-54. Museo Arqueológico Dr. Osvaldo F. A. Menghin. Municipalidad de Chivilcoy. Casa de la Cultura. Chivilcoy.

Aguerre, A. M. 2003. La Martita; ocupaciones de hace 8000 años en la Cueva 4. Arqueología y paleoambiente en la Patagonia Santacruceña Argentina. (Compiladora A. M. Aguerre): 29-61. Talleres Gráficos Offset. Bs. As

Aguerre A. M. y K. Patiño. 1991. Análisis tipológico y tecnológico del material lítico de la capa 3 del alero Cárdenas. Revista Arqueología 1: 210 a 213. Buenos Aires.

Akoshima, K. 1981. An experimental study of microflaking. Report of Tohoku University microflaking research team (English summary). Kokogaku Zasshi 66, 1-27.

Álvarez, M. 2003. Organización tecnológica en el Canal 
de Beagle. El caso Túnel (Tierra del Fuego, Argentina). Tesis Doctoral. Facultad de Filosofía y Letras. Universidad de Buenos Aires. MS.

Álvarez, M. 2004. Prácticas tecnológicas durante las ocupaciones tempranas del Canal de Beagle. Libro de resúmenes. XV Congreso Nacional de Arqueología Argentina Río Cuarto, Córdoba. pág. 130.

Álvarez M., A. Lasa y E. Mansur 2000. La explotación de recursos naturales perecederos. Análisis funcional de los raspadores de la costa norte del Canal de Beagle. Relaciones de la Sociedad Argentina de Antropología XXV (NS):275-296. Buenos Aires, Argentina.

Aschero, C. A. 1975. Ensayo para una clasificación morfológica de artefactos líticos aplicada a estudios tipológicos comparativos. Informe al CONICET No 5 . Inédito. Argentina.

Aschero, C. A. 1983. Ensayo para una clasificación morfológica de artefactos líticos aplicada a estudios tipológicos comparativos. Apéndice A-C. Revisión. Cátedra de Ergología y Tecnología (FFyL-UBA) Buenos Aires, MS.

Aschero, C. A. 1987. Tradiciones culturales en la Patagonia Central -una perspectiva arqueológica-. Comunicaciones de las Primeras Jornadas de Arqueología de la Patagonia, Serie Humanidades 2:17-26. Gobierno de la Provincia del Chubut, Dirección de Impresiones Oficiales, Rawson, Chubut.

Aschero, C. A. y S. Hocsman 2004. Revisando cuestiones tipológicas en torno a la clasificación de artefactos bifaciales. Temas de Arqueología. Análisis Lítico. Mariano Ramos, Alejandro Acosta y Daniel Loponte (compiladores), 7-25. Universidad Nacional de Lujan. Lujan.

Bamforth, D. 1988. Investigating microwear polishes with blind tests: the Institute results in context. Journal of Archaeological Science 15: 11-23.

Bamforth, D. M., Burns, G. R. y C. Woodman 1990. Ambiguous use-traces and blind test results: new data. Journal of Archaeological Science 17: 413-430.

Beyries, S., Delamare, F. y J.C. Quantin 1988. Traceologie et rugosimetrie tridimensionelle. Industries lithiques: traceologie et technologie, 2: 115-132S. Beyries, Ed. British Archaeological Reports International Series 411.

Cardich, A., R. Paunero y A. Castro 1994. Análisis de los conjuntos líticos de la Cueva 2 de Los Toldos (Santa Cruz, Argentina). Anales del Instituto de la Patagonia, 22: 149173, Punta Arenas, Chile.

Cattáneo G. R. 2002. Una Aproximación a la Organización de la Tecnología Lítica entre los Cazadores- Re- colectores del Holoceno Medio/Pleistoceno Final en la Patagonia Austral, Argentina. Universidad Nacional de La Plata. Facultad de Ciencias Naturales y Museo. Tesis Doctoral. MS.

Cattáneo G. R. 2006. Tecnología Lítica del Pleistoceno Final/Holoceno Medio Un Estudio de los Cazadores-Recolectores de la Patagonia Austral (Argentina). British Archaeological Reports S1580.

Cattáneo G. R. 2007. Caracterizaciones morfo-tecnológicas y funcionales de artefactos líticos: un caso de estudio en el área arqueológica Río Pinturas, Santa Cruz, Argentina. Pacarina (Actas del XVII Congreso Nacional de Arqueología Argentina): 445-452. San Salvador de Jujuy, Argentina.

Cattáneo G. R. 2009. Análisis funcional de base microscópica para la determinación de enmangues en raspadores del sitio Cueva de las Manos (Santa Cruz, Argentina). MS. en preparación.

Cattáneo G. R. y A. M. Aguerre 2008. Nuevos avances en caracterizaciones morfo-funcionales de artefactos líticos en el área arqueológica río Pinturas, Santa Cruz, Argentina. Resúmenes del las VII Jornadas de Arqueología de la Patagonia. Ushuaia, Tierra del fuego, Argentina.

Cattáneo, G. R., y M. Fernández 2005. Programa de Observación de Microhuellas de uso en Instrumentos Líticos y su Aporte a la discusión de la funcionalidad de sitios: datos experimentales y arqueológicos. Problemáticas de la arqueología contemporánea. Publicación del XV Congreso Nacional de Arqueología Argentina Tomo II: 449-456, Río Cuarto, Córdoba.

Cattáneo, G. R., G. Guzmán, C. Di Lello, M. Calo y A. M. Aguerre 2007a. Análisis por FT-IR de residuos orgánicos en instrumentos líticos provenientes del sitio Cueva de las Manos, capa 6, Río Pinturas (Santa Cruz, Argentina). Actas del $2^{\circ}$ Congreso Argentino y $1^{\circ}$ Latinoamericano de Arqueometría.

Cattáneo, G. R., P. Meilán, D. Gulich, M. Fernández y M. Garavaglia 2007b. Microscopia láser confocal de barrido (CLSM) aplicada al estudio de microhuellas de utilización en instrumentos líticos experimentales: una perspectiva cuantitativa. Arqueología de Fuego-Patagonia. Levantando piedras, desenterrando huesos... y develando arcanos: 327-342. Ediciones CEQUA. Editado por Flavia Morello, Mateo Martinic, Alfredo Prieto y Gabriel Bahamonde. Punta Arenas, Chile.

Cattáneo, G. R., P. Meilán, D. Gulich, M. Fernández y M. Garavaglia 2007c. Microscopia láser confocal de barrido (CLSM) y software de reconocimiento de imágenes aplicadas al estudio funcional de artefactos líticos: una perspectiva cuantitativa. Actas del $2^{\circ}$ Congreso Argentino 
y $1^{\circ}$ Latinoamericano de Arqueometría.

Close, A. E. 2002, Backed Bladelets Are a Foreign Country. Archeological Papers of the American Anthropological Association 12 (1):31-44.

Collin, F. y P. Jardón-Giner 1993. Travail de la peau avec des grattoirs emmanchés. Réflections sur des bases expérimentales et ethnographiques. Traces et fonctions: les gestes retrouvés. Colloque International de Liége. Editions ERAUL, 50:105-117.

Dumont, J. V. 1982. The quantification of microwear traces: A new use for interferometry. World Archaeology 14: 206-217.

Durán, V. 1990. Estudio tecno-tipológico de los raspadores del sitio El Verano- Cueva 1 (Area de La Martita). Prov. De Santa Cruz. Anales de Arqueología y Etnología 41/42:129-163. Mendoza

Evans, A. A. y R. E. Donahue 2008. Laser scanning confocal microscopy: a potential technique for the study of lithic microwear. Journal of Archaeological Science 35: 2223-2230

Gendel, P. A. y L. Pirnay 1982. Microwear analysis of experimental stone tools: further test results. In (D. Cahen, Ed.) Tailler pourquoi faire: Prèhistoire et technologie lithique II, Recent progress in microwear studies. Tervuren: Studia Praehistorica Belgica 2, Museè royal de l'Afrique centrale, pp. 251-265.

Grace, R. 1989. Interpreting the Function of Stone Tools: The Quantification and Computerization of Microwear Analysis. Oxford: British Archaeological Reports International Series 474.

Grace, R. 1990. The limitations and applications of use wear analysis. En (B. Graslund, H. Knutsson, K. Knutsson \& J.Taffinder, Eds) The Interpretive Possibilities of Microwear Analysis.Uppsala: AUN 14, Societas Archaeologica Upsaliensis, pp. 9-14.

Grace, R. 1993. The use of expert systems in lithic analysis. Traces et fonction: Les Gestes Retrouve's, P. C. Anderson, S. Beyries, M. Otte \& H. Plisson, Eds 2: 389-400. Liege: College Internationalde Liege, Editions Eraul, no. 50, Centre de Recherches Archeologiques du CNRS, Etudes et Recherches Archeologiques del'Universite' de Liege,.

Grace, R. 1996. Review article: use wear analysis: the state of the art. Archaeometry 38: 209-229.

Grace, R., Graham, I. D. G. y M. H. Newcomer 1985. The quantification of microwear polishes. World Archaeology 17: 112-120.
Grace, R., Graham, I. D. G. y M. H. Newcomer 1987. The mathematical characterization of wear traces on prehistoric flint tools. The Human Uses of Flint and Chert: Papers from the Fourth International Flint Symposium. 63-69.G. de G. Sieveking y M. Newcomer, Eds. Cambridge University Press.

Gradin, C. J., Aschero, C. A. y A. M. Aguerre 1976. Investigaciones arqueológicas en la Cueva de las Manos, Alto río Pinturas, Santa Cruz. Relaciones de la Sociedad Argentina de Antropología X(NS): 201-250. Buenos Aires, Argentina.

Gradin, C. J., Aschero, C. A. y A. M. Aguerre 1979. Arqueología del Área Río pinturas. Provincia de Santa Cruz. Relaciones de la Sociedad Argentina de Antropología XIII (NS): 183-228. Buenos Aires, Argentina.

Gulich D. y N. Lofeudo 2005. Programa PHILOS. Desarrollo para el Ciop. Laboratorio de Procesamiento Láser (CIC-UNLP-CONICET).

Guraieb A. G. 2008. Variaciones temporales en los conjuntos de raspadores de la secuencia de ocupaciones de Cerro de los Indios 1, Lago Posadas, Santa Cruz". Libro de Resúmenes, pp. 31. VII Jornadas de Arqueología de la Patagonia. Ushuaia.

Hayden, B. 1986. Use and Misuse: The analysis of Endscrapers. Lithic Technology 15 (2):82-89.

Holley, G. y T. Del Bene 1981. An evaluation of Keeley's microwear approach. Journal of Archaeological Science 8: 337-352.

Hurcombe, B. 1988. Some criticism and suggestions in response to Newcomer et al. (1986). Journal of Archaeological Science 1: 1-10

Jardón-Giner, P. y Sacchi, D. 1994. Traces d' usage et indices de réaffutages et d' emmanchements sur des grattoirs magdaléniens de la Grotte Gazel Á Sallélles-Cabardes (Aude, France). L'Anthropologie 98 (2-3): 427-446.

Keeley, L. H. 1974. Technique and methodology in microwear studies: a critical review. World Archaeology 5: 323-336.

Keeley, L. H. 1976. Microwear on flint: some experimental results. Second International Symposium on Flint. 49-51F. Engelen, Ed. Maastricht: Nederlands Geologische Vereniging.

Keeley, L. H. 1978. Microwear polishes on flint: some experimental results. Lithics and Subsistence: The Analysis of Stone Tool Use in Prehistoric Economies. D. Davis, Ed. Nashville: Vanderbilt University, Publications in Anthropology No. 20, pp. 163-178. 
Keeley, L. H. 1980. Experimental Determination of Stone Tool Uses. A Microwear Analysis. Prehistory, Archaeology and Ecology Series. The University of Chicago Press.

Keeley, L. H. y M. H Newcomer 1977. Microwear analysis of experimental flint tools: a test case. Journal of Archaeological Science 4: 29-62.

Kimball, L. R., Kimball, J. F. y P. E. Allen 1995. Microwear polishes as viewed through the atomic force microscope. Lithic Technology 20(1): 6-28.

Knutsson, K., Dahlquist, B. y H.Knutsson 1988. Patterns of tooluse; the microwear analysis of the quartz and flint assemblage from the Bjurselet Site, Vasterbotten, Northern Sweden. Industries lithiques: Traceologie et Technologie, 1: 253-294. S. Beyries, Ed. British Archaeological Reports International Series 411.

Leipus, M. 2001. Análisis de rastros de uso experimentales en materias primas líticas de la Región Pampeana. Arqueología Uruguaya hacia fines del milenio, Tomo I: 491-503. Colonia del Sacramento, Uruguay.

Leipus, M. 2004. Tendencias en el uso de los artefactos líticos en la Subregión Pampa Húmeda: relación entre morfología y función a partir del análisis de microrrastros de utilización. El Área Pampeana: Su Pasado Arqueológico. C. J. Gradín y F. Oliva Editores: 123-130. Laborde Editor.

Leipus M. y Mansur M. E. 2007. El análisis funcional de base microscópica aplicado a materiales heterogéneos. Perspectivas metodológicas para el estudio de las cuarcitas de la Región Pampeana. Arqueología de las Pampas. Bahía Blanca: Universidad Nacional del Sur. p. 179-200.

Lepistö, L., Kunttu, I., Autio, J. y A. Visa, 2003. Rock Image Classification Using Non-Homogeous Textures and Spectral Imaging. WSCG 2003. The 11-th International Conference in Central Europe on Computer Graphics, Visualization and Computer Vision.

Mansur M. E. 1999. Análisis de instrumental lítico: problemas de formación y deformación de rastros de uso. Actas del XII Congreso Nacional de Arqueología Argentina (1):355-366. La Plata.

Mansur M.E. y A. Lasa 2004. Tecnología y Función el el IV componente de Tunel I (Tierra del Fuego). Libro de resúmenes del XV Congreso Nacional de Arqueología Argentina. Río Cuarto, Córdoba. Pág. 131.

Mansur M. E. y R. Srehnisky 1996. El alisador basáltico de Shamakush I: microrrastros de uso mediante el análisis de imágenes digitalizadas. Relaciones de la Sociedad Argentina de Antropología. XXI: 267-288, Buenos Aires.

Moss, E. H. 1987. A review of "Investigating microwear polishes with blind tests". Journal of Archaeological Science 14: 473-481.

Newcomer, M. H. y L. H. Keeley 1979. Testing a method of microwear analysis with experimental flint tools. B. Hayden, Ed., Lithic Use-Wear Analysis. New York: Academic Press, pp. 195-206.

Newcomer, M. H., Grace, R. y R. Unger-Hamilton 1986. Investigating microwear polishes with blind tests. Journal of Archaeological Science 13: 203-217.

Newcomer, M. H., Grace, R. y R. Unger-Hamilton 1987. Microwear polishes, blind tests and texture analysis. The Human Uses of Flint and Chert: Papers from the Fourth International Flint Symposium. 253-263. G. Sieveking, M. Newcomer, Eds. Cambridge University of Cambridge Press.

Newcomer, M. H., Grace, R. y R. Unger-Hamilton 1988. Microwear methodology: a reply to Moss, Hurcombe and Bamforth. Journal of Archaeological Science 15: 25-33.

Paunero, R. y A. Castro 1997. Análisis lítico funcional del Componente Cultural Inferior del sitio C3T.C1. Ea. San Rafael, Santa Cruz, Argentina. Libro de resúmenes del XII Congreso Nacional de Arqueología Argentina: 112, La Plata, Bs. As.

Paunero, R. y A. Castro 2001. Análisis lítico y funcionalidad del Componente Inferior del sitio Cueva 3, localidad arqueológica Cerro Tres Tetas, provincia de Santa Cruz, Argentina. Anales del Instituto de la Patagonia, Serie Ciencias Humanas, 29: 189-206. Punta Arenas, Chile.

Partio, B., Cramariuc, M., Gabbouj, L. y A. Visa. 2002. Rock Texture Retrieval using Gray Level Co-occurrence Matrix. NORSIG-5th Nordic Signal Processing Symposium, On Board Hurtigruten M/S, Trollfjord, Noruega.

Phillibert, J. 1994. L' ocre et le traitement des peaux: révision $d^{\prime}$ une conception traditionnelle par l' analyse fonctionnelle des grattoirs ocrés de la Balma Margineda (Andorre). L'Anthropologie 98 (2-3): 447-453.

Rees, D., Wilkinson, G. G., Grace, R. y C. R. Orton 1991. An investigation of the fractal properties of flint microwear images. Journal of Archaeological Science 18: 629-640.

Russ, J. C. 1993. Light scattering from fractal surfaces. Journal of Computer-Assisted Microscopy: 171-189.

Russ, J. C. 1994. Fractal Surfaces. New York: Plenum Press.

Semenov, S.A. 1964. Prehistoric Technology. Moonraker Press, London. 
Stemp, W. J. y M. Stemp 2001. UBM laser profilometry and lithic use-wear analysis: a variable length scale investigation of surface topography. Journal of Archaeological Science 28: 81-88.

Stemp, W. J. y M. Stemp 2003. Documenting Stages of Polish Development on Experimental Stone tools: Surface caracterization by Fractal Geometry using UBM Laser Profilometry. Journal of Archaeological Science 30: 287-296

Vaughan, P. C. 1981. Lithic microwear experimentation and the functional analysis of a Lower Magdalenian stone tool assemblage. Tesis Doctoral, University of Pennsylvania.

Vaughan, P. C. 1985.Use-Wear Analysis of Flaked Stone Tools. The University of Arizona Press.
Walker, R.F., P. Jackway, y I. D. Longstaff 1995. Improving co-occurrence matrix feature discrimination. Proceedings DICTA-95 Digital Image Computing: Techniques and Applications, Anthony Maeder and Brian Lovell, Eds., Brisbane, pp.643-648.

Winiarska-Kabaonska, M. 1988. Examination of hafting traces on end-scrapers concentratios III/75 from the site of Wojnovo "a" (western Poland). Industries Lithiques. Tracéologie et technologie, 1: 53-68. Beyries, Ed. BAR International Series 411 (ii). Oxford.

Yacobaccio, H. D 1988. Multifunction and morphological homogeneity: a Patagonian case study. Industries Lithiques. Tracéologie et technologie, 1: 53-68. Beyries, Ed. BAR International Series 411 (ii). Oxford. 